US Army Corps of Engineers ${ }_{\circledast}$

Engineer Research and Development Center

Urban Flood Damage Reduction and Channel Restoration Development and Demonstration Program for Arid and Semi-Arid Regions (UFDP); Southwest Urban Flood Damage Program (SWDP)

\title{
Coupling of Hydrologic/Hydraulic Models and Aerial Photographs Through Time, Rio Grande Near Albuquerque, New Mexico: Report Documentary 2007 Work
}

Benjamin Swanson, Grant Meyer, and Julie Coonrod

August 2010

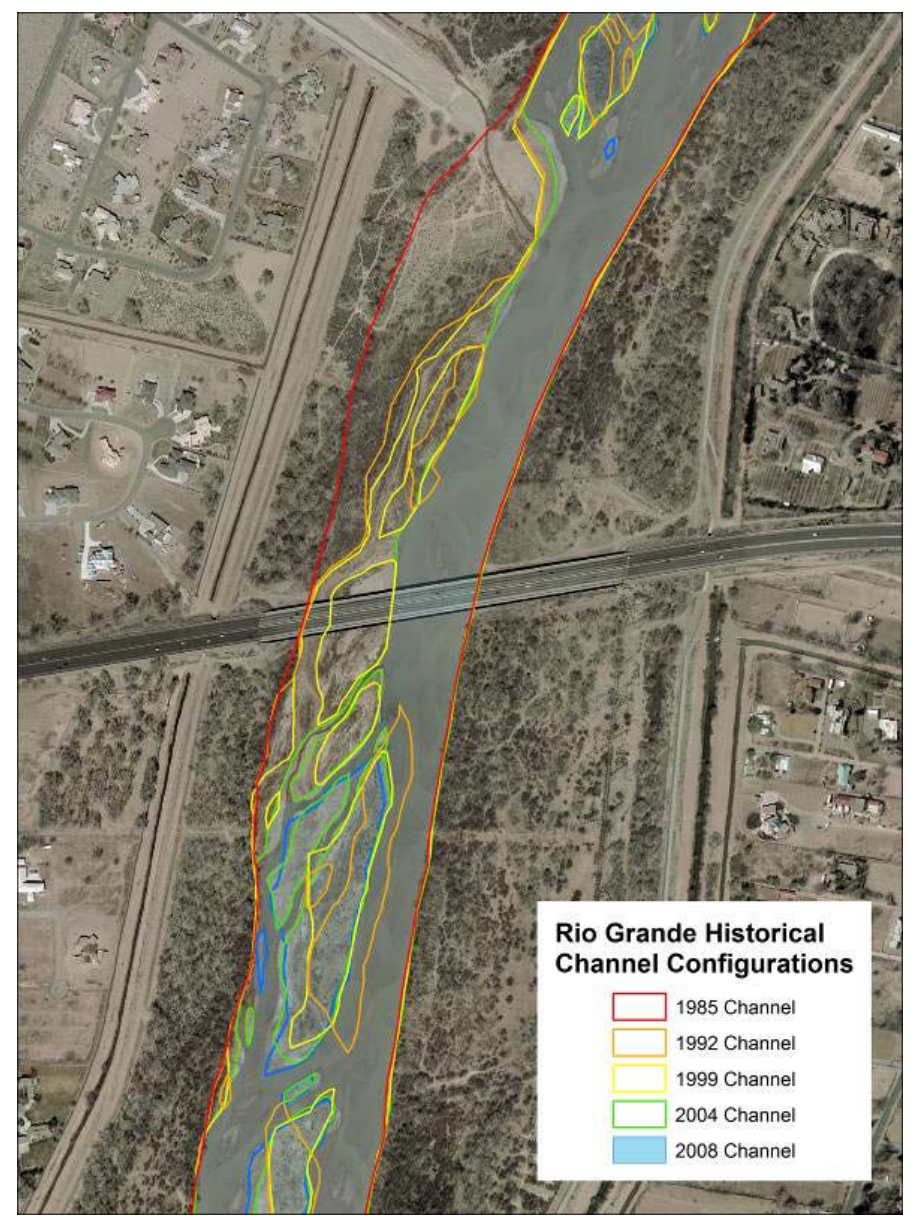

Aerial photograph of Rio Grande at Paseo del Norte Bridge showing historical channel change downstream of Calabacillas Arroyo. 2004 Aerial Photograph from Bernalillo County, GIS Department, Bernalillo County, NM 
Urban Flood Damage Reduction and Channel

Restoration Development and Demonstration

August 2010

Program for Arid and Semi-Arid Regions (UFDP);

Southwest Urban Flood Damage Program (SWDP)

\section{Coupling of Hydrologic/Hydraulic Models and Aerial Photographs Through Time, Rio Grande Near Albuquerque, New Mexico: Report Documentary 2007}

Benjamin Swanson, Grant Meyer, and Julie Coonrod

University of New Mexico

MSC01 1070 Civil Engineering

Albuquerque, NM 87120

Final report

Approved for public release; distribution is unlimited.

Prepared for U.S. Army Corps of Engineers

Washington, DC 20314-1000

Monitored by Coastal and Hydraulics Laboratory

U.S. Army Engineer Research and Development Center

3909 Halls Ferry Road, Vicksburg, MS 39180-6199 


\begin{abstract}
This phase of the study investigated the relation of average and peak flows in the Rio Grande to changes in channel, sand bar, and island widths as measured on historical aerial photographs taken from 1972 to 2006. The study reach lies between Bernalillo Bridge and the Isleta Diversion Dam, with a focus on the river between the North and South Albuquerque Metropolitan Arroyo Flood Control Authority (AMAFCA) Diversion Channels. Digitized and georeferenced photographs were analyzed using a geographic information system (GIS), with particular attention paid to quantifying potential measurement error and its propagation through estimates of channel areas and bank erosion rates. Average active channel widths decreased from $169 \pm 5 \mathrm{~m}$ in 1972 to $130 \pm 5 \mathrm{~m}$ in 2006. Narrowing concentrated in the upper study reach and in areas where the 1972 channel was relatively wide. Variability in channel width also decreased over the study period. Decreases in channel width and area coincide with periods of low flows, although the area changes are associated with large errors. Island areas have increased since 1972, although islands per se were also lost during the later study period by bank attachment. Bank erosion estimates have large associated errors. Erosion rates appear to be generally decreasing over time, but accelerated during the 2005 high flows.
\end{abstract}

Initial testing of a method for generating channel depth data from black and white aerial photography was also conducted. Overall, however, the Rio Grande is a difficult river on which to apply this method because of turbidity, exposed sand bars, and a rapidly shifting bed. Further work including synchronized channel depth measurements and aerial photography during favorable conditions is needed.

DISCLAIMER: The contents of this report are not to be used for advertising, publication, or promotional purposes. Citation of trade names does not constitute an official endorsement or approval of the use of such commercial products. All product names and trademarks cited are the property of their respective owners. The findings of this report are not to be construed as an official Department of the Army position unless so designated by other authorized documents. 


\section{Contents}

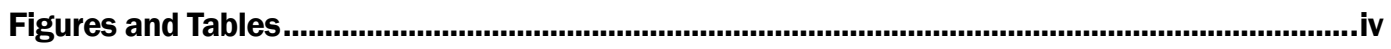

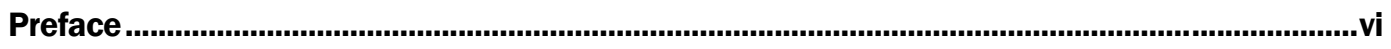

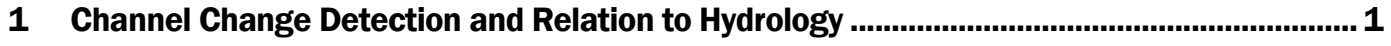

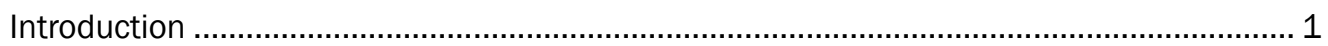

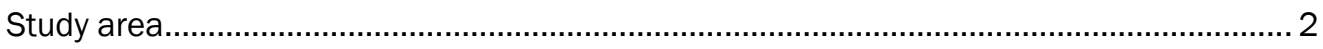

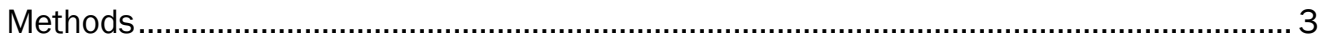

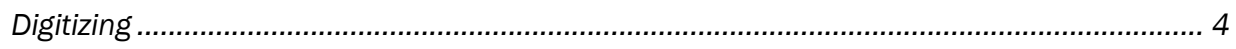

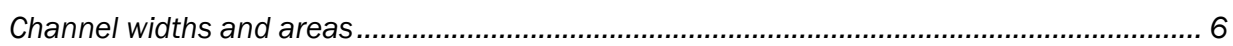

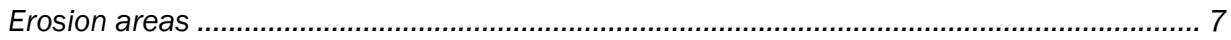

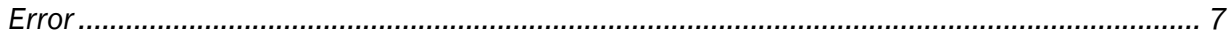

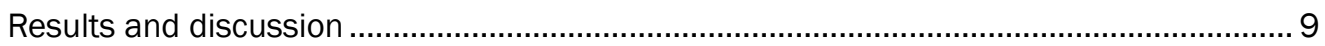

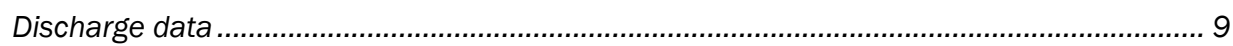

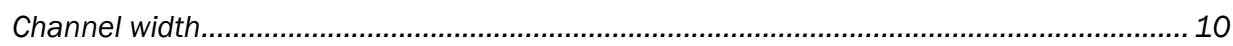

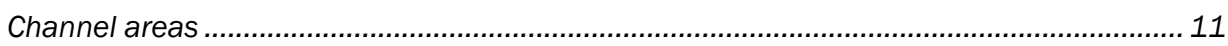

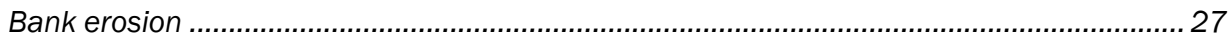

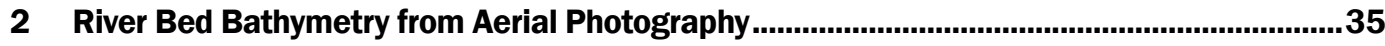

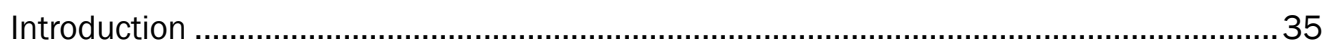

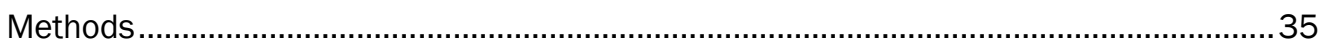

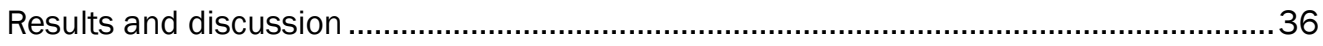

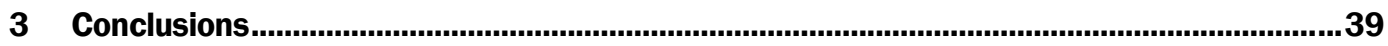

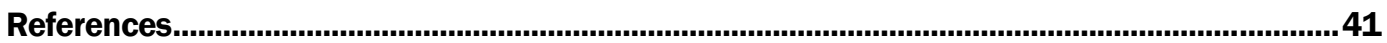

Report Documentation Page 


\section{Figures and Tables}

\section{Figures}

Figure 1. Map of Albuquerque, NM, depicting study reach from north to south of AMAFCA Diversion Channel.

Figure 2. Histogram of differences between the 1992 and 2006 total channel widths (m). Positive numbers indicate channel widening and negative numbers indicate narrowing. The dotted gray lines represent standard deviations and the blue lines represent error.

Figure 3. Hydrograph from the USGS Rio Grande at Albuquerque, NM, gage (19722007; site 08330000). Step plots' tread represents average discharge values between photograph periods and the riser represents photograph date, where solid line is average peak discharge between photographs and dashed line is average daily discharge between photograph periods.

Figure 4. Change in average total channel width from 1972 to 2006. Average total channel widths decrease over study period. Discharge metrics shown as in Figure 3.

Figure 5. Change in average active channel width (excluding islands) from 1972 to 2006. Average active channel widths decrease over study period. Discharge metrics shown as in Figure 3 .

Figure 6. Channel change locations from 1992 to 2006. Warm colors (red, orange) indicate areas where channel is narrowing (bar attachment and expansion) and cool colors (violet, blue) indicate widening (bank erosion). Channel has narrowed in upper third (North AMAFCA Diversion Channel to Paseo del Norte), middle (above I-40), and downstream end (South AMAFCA Diversion Channel) of study reach.

Figure 7A (top) and 7B (bottom). Change in active channel width downstream of Bernalillo Bridge.

Figure 7C (top) and 7D (bottom). Change in active channel width from Arroyo de la Baranca through Corrales.

Figure $7 \mathrm{E}$ (top) and 7F (bottom). Change in active channel width from Corrales to below the North Diversion Channel. Channel narrowing up and downstream of diversion channel has been relatively active in last 10 years.

Figure 7G (top) and $7 \mathrm{H}$ (bottom). Change in active channel width from Alameda Bridge to 1,000 m upstream of Montano Bridge. Sediment from Arroyo de las Calabacillas contributes to narrowing near and downstream of arroyo.

Figure $7 \mathrm{I}$ (top) and $7 \mathrm{~J}$ (bottom). Change in active channel width from Montano Bridge to I-40.

Figure 7K (top) and 7L (bottom). Change in active channel width through Old Town area to Bridge Boulevard. This reach appears relatively stable.

Figure 7M (top) and 7N (bottom). Change in active channel width from downstream of Bridge Boulevard to South Diversion Channel. Channel widths are relatively stable to below Rio Bravo Bridge, but narrowing has occurred above diversion channel.

Figure 70 (top) and 7P (bottom). Change in active channel width from South AMAFCA Diversion Channel to Los Padillas.

Figure 7Q (top) and 7R (bottom). Change in active channel width from Los Padillas to Isleta Diversion Dam.

Figure 7S (top) and 7T (bottom). Change in active channel width from Isleta Diversion 
Figure 8. Change in total channel area (including island area) over time. Error is \pm 3 percent. Discharge metrics shown as in Figure 3 .

Figure 9. Change in active channel area (excluding island area) over time. Total channel area decreases over study period. Error varies from 3 to 5 percent. Discharge metrics as in Figure 3.

Figure 10. Rate of change in total channel area (including island area) between photograph years. Negative values indicate channel contraction. Although within the error (gray), the steps in both change in area rates and average peak discharge (red) are similar. Higher peak discharges appear to maintain channel area, whereas lower flows result in contracting. Discharge metrics shown as in Figure 3.

Figure 11. Rate of change in active channel area (excluding island area) between photograph years. Negative values indicate channel contraction. Although within the error (gray), the steps in both change in area rates and average peak discharge (red) are similar. Discharge metrics as in Figure 3.

Figure 12. Change in island area over time. Island area has increased steadily since 1985. The "plateau" from 2002 to 2006 is in part due to island attachment to banks, removing island area. Discharge metrics as in Figure 3.

Figure 13. Rates of change in island area between photograph years. Although within the error (gray), rates of island development and expansion are relatively high between 1985 and 2002. Area (red) appears to decrease during recent drought and 2005 flood, in part due to loss of area through bank attachment during dry years. Discharge metrics shown as in Figure 3.

Figure 14. Erosion rates between photograph years. All values are within calculated error. Erosion rates seem to decrease through 2002, and then increase through the 2005 flood. Discharge metrics shown as in Figure 3.

Figure 15. Erosion rates between 1985 and each photograph year. Downward trend suggests that erosion rate is decreasing over time. Discharge metrics as in Figure 3.

Figure 16. Distribution of relative high bank erosion along study reach (left). Most of these areas are associated with large expanding or attached bars, such as those at South Diversion Channel (right).

Figure 17. Erosion rates at individual bank locations. Locations are provided in Figure 16.............32

Figure 18. Regression of 2001 air photographs reflectance values and cross-section depths (right) and resulting modeled depths (left).

Figure 19. Relationship between photograph reflectance values and depth at USBR cross-section CO-27.

Figure 20. Topographic data derived from 0.6-m (2-ft) contours (yellow) and comparison of air photograph reflectance values and measured cross-section depths (red line at cross-section). Although not quantified at this stage of analysis, the final DEM (right) revealed similar plan view channel features (red ovals) as seen in photograph (left).

\section{Tables}

Table 1. Aerial photography sets covering the Albuquerque Reach of the Rio Grande. Photographs are available for most decades since 1935, and imagery has been collected at least every other year since 1996. Yellow rows indicate photograph sets used for this study.

Table 2. Statistics associated with active channel widths for each photographic year, in meters. 


\section{Preface}

The University of New Mexico (UNM) is conducting this study under the direction of the U.S. Army Engineer Research and Development Center (ERDC), Coastal and Hydraulics Laboratory (CHL), Technical Programs Office. Funding was provided by the Urban Flood Damage Reduction and Channel Restoration Development and Demonstration Program for Arid and Semi-Arid Regions (UFDP) and Southwest Urban Flood Damage Program (SWDP) of the USACE General Investigations Research and Development Program. Authorization of the USACE to conduct research and development is codified in 10 U.S.C. 2358.

Work was performed under the general supervision of Dr. Lisa Hubbard, UFDP and SWDP Program Manager, CHL; Dr. J ack Davis, Technical Director for Flood and Coastal Storm Damage Reduction; William R. Curtis, Program Manager of the Flood and Coastal Storm Damage Reduction, Research and Development Program; Dr. William D. Martin, Director CHL, and J ose Sanchez, Deputy Director, CHL. This report was prepared by Benjamin Swanson, Dr. Grant Meyer, and Dr. J ulie Coonrod of the University of New Mexico, and a technical review was conducted by Darrell Eidson, U.S. Army Engineer District, Albuquerque, and MegJ onas and Dr. Lisa Hubbard both of ERDC-CHL. J. Holley Messing, Coastal Engineering Branch, CHL, completed final formatting of the report.

COL Gary E. J ohnston, was Commander and Executive Director of ERDC. Dr. J effery P. Holland was Director. 


\section{Channel Change Detection and Relation to Hydrology}

\section{Introduction}

A commonly held view in river science is that channels evolve to carry their specific combination of water and sediment discharges. Determining how river systems adjust to altered sediment loads or hydrology is, therefore, a primary research concern of fluvial geomorphologists and engineers. One common way to begin such analyses is to review river planform changes on historical photographs. Aerial photographs are an important source of information on river systems, and sequential sets of historical air photographs and satellite imagery are often used to produce quantitative data on channel planform, floodplain, and bar evolution (e.g., Lapointe and Carson 1986; Trimble 1991; Lawler 1993; Gurnell 1997; Gilvear et al. 1999; Surian 1999; Graf 2000; Winterbottom and Gilvear 1997; O'Connor et al. 2003; and others). These studies are especially important when investigating economically vital rivers such as the Rio Grande, which has experienced numerous perturbations related to water withdrawals and flood control, and where altered channel form and process may affect adjacent infrastructure.

Over the last decade, changes in Rio Grande channel planform have been investigated by numerous researchers (e.g., Mussetter Engineering, Inc. (MEI) 2003, 2006; Richard and J ulien 2003; Makar et al. 2006). Although these studies have documented the trend of channel narrowing in the study reach, they have concentrated primarily on long-term trends over relatively long reaches of the river. Major factors, such as altered hydrology, sediment trapping by dams, and vegetation encroachment have been identified, but little detailed work has been done on ongoing processes with respect to narrowing and erosion along the reach of river flowing through Albuquerque, NM, especially how these changes relate to the hydrology. The overall purpose of this work is to couple fluvial system changes that can be documented in aerial imagery with hydrologic and hydraulic models of the system. Here, we investigated the relation of average and peak flows to changes in channel widths, and sand bar and island widths. We have also conducted initial testing of a method for generating channel depth data from black and white aerial images. 


\section{Study area}

The study reach includes approximately $29 \mathrm{~km}$ of the Rio Grande flowing through Bernalillo County and the city of Albuquerque, NM (Figure 1). Most of the work focuses on the reach of river between the north and south Albuquerque Metropolitan Arroyo Flood Control Authority (AMAFCA) Diversion Channels, where the photograph sets used in the study overlap. Depending on the extent of the photographic coverage, channel data were also acquired from the Bernalillo Bridge (Highway 550) to the Isleta Diversion Dam. Within the reach, the river and its floodplain lie between earthen levees that protect adjacent urban and suburban areas. A mix of native cottonwood (Populus spp.), exotic Russian olive (Elaeagnus angustifolia), and salt cedar (Tamarix ramosissima) dominate floodplain and bank vegetation in this area.

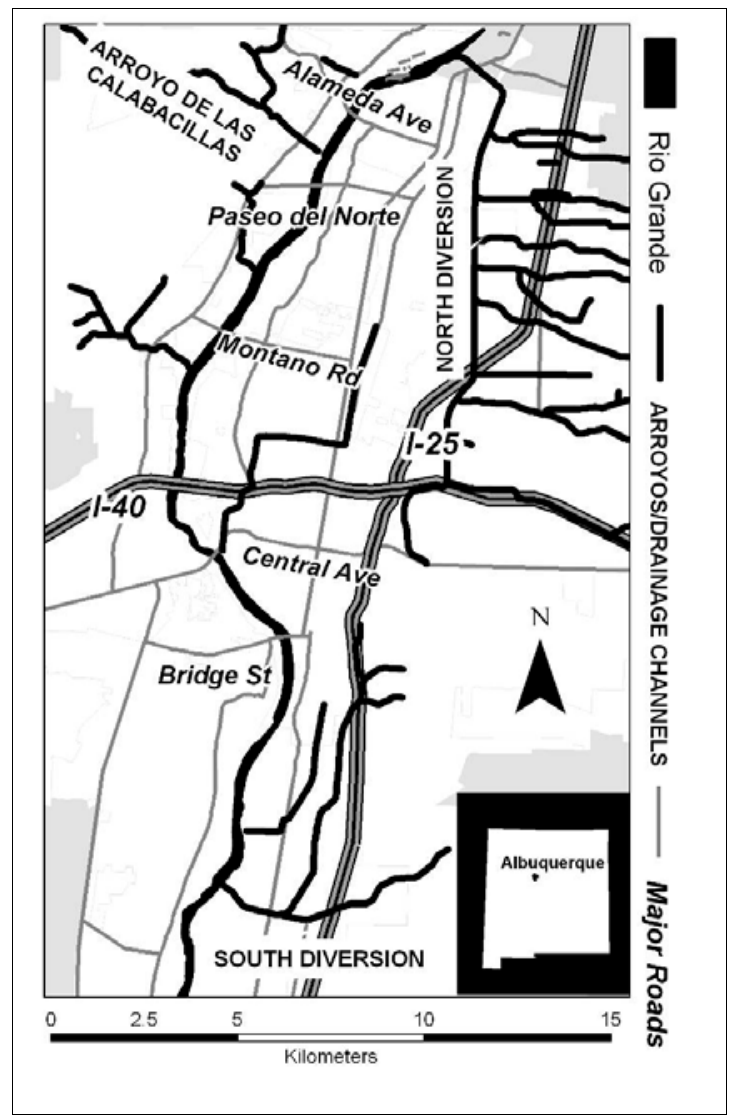

Figure 1. Map of Albuquerque, NM, depicting study reach from north to south of AMAFCA Diversion Channel. 
From early European settlement through the early 1900s, the Rio Grande through the study reach was primarily a wide, sand-bedded channel that supported numerous wetlands, cottonwood (Populus spp.) galleries, and expanses of salt grass (Scurlock 1998). Major modifications to the river began with channelization and irrigation diversions in the 1920s. Since then, channel geomorphology has been altered via dredging and channelization, and water and sediment supplies have been impacted by municipal use and the construction of dams and irrigation channels along the main stem and major tributaries upstream (Lagasse 1994; MEI 2003; Richard and J ulien 2003; Makar et al. 2006). These impacts have resulted in numerous channel changes within the reach, including narrowing, degradation, and an increase in vegetated islands (MEI 2003, 2006; Ortiz 2004; Makar et al. 2006; Massong et al. 2006).

Most of the studies documenting these changes along the Rio Grande have utilized aerial photographs. Probably the largest imagery-based project, the U.S. Department of the Interior, Bureau of Reclamation's (USBR) Rio Grande Planform Study, used maps and photographs from each decade between 1918 to 2001 to document geomorphic and vegetative changes along the river from Valende to Otowi and from Cochiti Dam to Elephant Butte Reservoir, NM (Oliver 2004; Makar et al. 2006). Data generated from the USBR project has been used in channel width modeling by investigators at Colorado State University (Leon 1998; Richard and J ulien 2003). The USBR has also used air photos to measure river bend evolution in relation to levee protection and other land use issues (Massong 2005; Massong and Makar 2006; Tashjian and Massong 2005). In addition, MEI used historic photographs and maps to evaluate general channel change (2003) and changes in vegetated and unvegetated bars (2006) along the middle Rio Grande, and related studies by Ortiz (2004) and Meyer and Hepler (2007) also used air photographs to document changes in vegetated bars. Finally, Bohannon Huston, an Albuquerque based engineering consulting firm, has been active in acquiring and utilizing imagery for mapping Bernalillo County, including water resources and vegetation (www.bhinc.com).

\section{Methods}

Aerial photographs covering the Albuquerque Reach of the Rio Grande have been collected by various agencies over the last 75 years, and many are publicly available in a digital, spatially referenced form (Table 1). The USBR obtained and digitized several sets of these photographs for the Rio Grande Planform Study (Oliver 2004; Makar et al. 2006). Bernalillo 
County has also been involved in photograph acquisition for land management and planning studies as part of the Mid-Region Council of Governments (MRCOG). Presumably, photographs of the river have been obtained for other MRCOG counties (Sandoval and Valencia), as well. Other imagery sets include U.S. Geological Survey (USGS) Digital Ortho Quarter Quads, and the U.S. Army Corps of Engineers (USACE) Quickbird satellite imagery. Additional imagery of the Rio Grande floodplain likely exists, but is not as easily accessible (contact the Earth Data Analysis Center at the University of New Mexico; http:// edac.unm.edu/ ).

The images used in this study (yellow-shaded rows in Table 1) span from 1972 to 2006, with no more than 4 years separating the photosets after 1992. Prior to the 1999 photographs, the image sets were black and white, but later sets were primarily color. The quality varied both between and within photographic sets. For instance, the 2004 photographs, although generally of good quality, had numerous sub-reaches of the river characterized by strong sunlight reflectance off the water (white pixels), making bar analyses impossible in these locations. The scale and stage at which each image was obtained also differed from set to set. Most of the images were of good quality and were generally well aligned with the other photographs (spatially referenced). Exceptions included offsets on the 2001 and 2006 USBR photographs, although most of these offsets were near the Isleta diversion dam, outside of the study area. The 1992 digital files were hard to interpret, mostly due to a lower digital resolution. For more detailed documentation on each data set, including processing information, consult the metadata associated with the digital source files.

\section{Digitizing}

Once obtained, the images were used to produce quantitative data characterizing the channel for each photograph year. Much of this work involved air photograph interpretation and on-screen digitization of channel banks and stable islands using a geographic information system (GIS) ArcInfo 9.1. The banks and stable bars on the 1992 to 2006 photographs were digitized by the author at a set scale of 1:2500, and the 1985 and 1972 data were obtained from the USBR. The USBR geodatabase also includes data from 1992, 2001, and 2002, but to maintain consistency, channel features from these photograph years were digitized by the author from Bernalillo County photographs. Visual inspection and random measurements of the final digitized channel for these years indicate that they match well with the USBR channel polygons ( $\pm 10 \mathrm{~m}$ ). 
Table 1. Aerial photography sets covering the Albuquerque Reach of the Rio Grande. Photographs are available for most decades since 1935 , and imagery has been collected at least every other year since 1996. Yellow rows indicate photograph sets used for this study.

\begin{tabular}{|c|c|c|c|c|c|c|c|c|c|c|}
\hline Photo Year & Date & Taken By & Taken For & $\overline{\text { Availability }}$ & Quality & Resolution & Color & Scale (1:X) & Spatial Reference & Discharge (cfs) \\
\hline 1935 & 1935 & NA & MRGP & USBR & Poor Contrast & 0.92 & B/W & 8000 & UTM NAD83 & NA \\
\hline 1949 & 1949 & 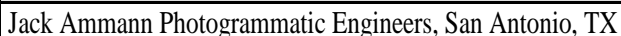 & MRGP & USBR & Adequate & 0.3 & $B / W$ & 5000 & UTM NAD83 & NA \\
\hline 1962 & $3 / 15 / 62$ & Abram Aerial Survey Corp., Lansing, MI & MRGP & USBR & Poor & 0.3 & $\mathrm{~B} / \mathrm{W}$ & 4800 & UTM NAD83 & 643 \\
\hline 1972 & March-72 & Limbaugh Engineers, Inc., Albuquerque, NM & MRGP & USBR & Poor Contrast & 1.22 & $\mathrm{~B} / \mathrm{W}$ & 4800 & UTM NAD83 & $150-913$ \\
\hline 1985 & $3 / 13 / 85$ & M\&I Consulting/Horizons, Inc, Ft. Collins, CO & MRGP & USBR & Poor Contrast & NA & $\mathrm{B} / \mathrm{W}$ & 4800 & UTM NAD83 & 2850 \\
\hline 1991 & $5 / 5 / 91$ & National Aerial Photography Program (NAPP) & USGS & RGIS & Adequate & 1 & $\mathrm{~B} / \mathrm{W}$ & 12000 & State Plane NAD83 & 2830 \\
\hline 1992 & $2 / 24 / 92$ & Koogle and Poules Engineering, Inc., Albuquerque, NM & MRGP & USBR & Poor Resolution/Error & 4 & $B / W$ & 4800 & UTM NAD83 & 329 \\
\hline 1996 & $10 / 6 / 96$ & National Aerial Photography Program (NAPP) & USGS & RGIS & Adequate & 1 & $\mathrm{~B} / \mathrm{W}$ & 12000 & UTM NAD83 & 635 \\
\hline 1999 & $6 / 1 / 99$ & Bohannon Husten, Inc., Albuquerue, NM & USACE & BERN & Good & 0.3 & Color & 12000 & State Plane NAD83 & 4550 \\
\hline 2001 & $2 / 13 / 01$ & Pacific Western Technologies, Ltd., Albuquerque, NM & MRGP & USBR & Good/High Error & 0.6 & $\mathrm{~B} / \mathrm{W}$ & 4800 & State Plane NAD83 & 687 \\
\hline 2001 & March-01 & ISTAR & NA & BERN & Poor Contrast & 0.3 & $\mathrm{~B} / \mathrm{W}$ & 12000 & State Plane NAD83 & $516-1170$ \\
\hline 2002 & $3 / 1 / 02$ & Pacific Western Technologies, Ltd., Albuquerque, NM & MRGP & USBR & Good & 3.9 & $\mathrm{~B} / \mathrm{W}$ & 4800 & UTM NAD83 & $404-603$ \\
\hline 2002 & $3 / 27 / 02$ & Pacific Western Technologies, Ltd., Albuquerque, NM & USGS & USGS/BERN & Good & 0.3 & Color & 15000 & UTM NAD83 & 443 \\
\hline 2002 & \begin{tabular}{|l|} 
August-02 \\
\end{tabular} & Pacific Western Technologies, Ltd., Albuquerque, NM & USBR & USBR & Good & 0.3 & Color & 15000 & UTM NAD83 & $412-1090$ \\
\hline 2004 & $3 / 27 / 04$ & Bohannon Husten, Inc., Albuquerque, NM & MRCOG & RGIS/BERN & Good & 0.3 & Color & 19000 & UTM NAD83 & 1550 \\
\hline 2004 & $10 / 31 / 04$ & Bohannon Husten, Inc., Albuquerque, NM & MRCOG & RGIS/BERN & Good & 0.3 & \begin{tabular}{|l|l|} 
Color \\
\end{tabular} & 19000 & UTM NAD83 & 179 \\
\hline 2004 & $7 / 1 / 04$ & Digital Globe, Longmont, CO & USACE & USACE & Good & 1.22 & Color-Quickbird & NA & State Plane NAD83 & 456 \\
\hline 2005 & $7 / 28 / 05$ & Bohannon Husten, Inc., Albuqueruque, NM & USGS & RGIS & Good & 1 & Color & 12000 & UTM NAD83 & 400 \\
\hline 2005 & June-05 & Aero-metric, Ft. Collins, CO & USBR & USBR & Good (Peak Flow) & 0.5 & Color Infrared & 4800 & UTM NAD83 & $4500-6510$ \\
\hline 2005 & $6 / 21 / 05$ & Digital Globe, Longmont, $\mathrm{CO}$ & USACE & USACE & Adequate & 0.6 & Color-Quickbird & $\mathrm{NA}$ & State Plane NAD83 & 4250 \\
\hline 2006 & $1 / 23 / 06$ & Aero-metric, Ft. Collins, CO & USBR & USBR & Good & 0.5 & \begin{tabular}{|c|} 
Color Infrared \\
\end{tabular} & 4800 & UTM NAD83 & 639 \\
\hline 2006 & $4 / 6 / 06$ & Bohannon Husten, Inc., Albuqueruque, NM & MRGOC & BERN & Good & 0.15 & Color & 12000 & State Plane NAD83 & 424 \\
\hline
\end{tabular}

MRGP Middle Rio Grande Project

MRCOG Mid-Region Council of Governments (www.mrcog-nm.gov)

RGIS New Mexico Resource Geographic Information System (rgis.unm.edu)

BERN Bernalillo County, NM GIS (www.bernco.gov)

USGS US Geologic Survey-Earth Resources Observation and Science (edc.usgs.gov/)

USBR US Bureau of Reclamation - Albuquerque Office

USACE US Army Corps of Engineers - Albuquerque Office 
The banks within the study area are often easy to identify on the air photographs, but issues involving overhanging trees, shadows, and other problems were common. In addition, differences in the shading and texture were also sometimes difficult to interpret, especially on bars where deposited debris, vegetation, rocks, and even wet sand, often appear similar. Delineating bars was also difficult due to inconsistent stages; however, higher discharges sometimes helped better define channel banks. Where possible, bank position, vegetation, and distances from infrastructure on the previous and subsequent photographs were referred to for help in determining positions. MEI's (2006) work on islands and bars showed that in-channel vegetation is difficult to remove under the present hydrology and channel configuration of the Rio Grande; therefore, bars with substantial new vegetation and little change from year to year were included as islands or new floodplain (no longer in the channel). This practice may overestimate island area, especially those digitized from the 2006 air photos. Finally, attempts at tracking unvegetated, exposed sandbars were unsuccessful due to different stages, turbidity, and photograph quality. It appears that many of the bars are located in roughly the same locations on sequential photographs, especially in areas of active island building and other sedimentation zones.

\section{Channel widths and areas}

Total channel widths ${ }^{1}$ were measured at $61-\mathrm{m}$ intervals by calculating the length of cross-section line segments lying within the channel areas in the GIS (clip geoprocessing tool). The cross sections were created by locating points along a generic center line based on the 2001 channel position, and then drawing a cross section at each point, stretching beyond the levees, that bisects the angle formed by the point and its two closest neighbors. Cross-section lines were of equal length and crossed the channel at $90 \mathrm{deg}$ $( \pm 10)$, except where the channel significantly deviates from the 2001 channel (large attached bars, obstructions, etc.). This method allows for cross sections to be created at any desired interval. Much of this process was done with XTools Pro 3.1.12 feature conversions tools, and ET GeoWizard $9.6^{3}$ polyline tools in the GIS, as well as with basic

\footnotetext{
${ }^{1}$ Within this document, "channel width" or "channel area" refers to a general channel characteristic, total channel width or area refer to the entire channel, including islands, and active channel width or area refer to the channel measurement minus the island measurement (at each cross-section for width and over the whole reach for area).

2 Data East, 2006; www.xtoolspro.com.

${ }^{3}$ ET Spatial Techniques, 2007; www.ian-ko.com.
} 
trigonometric calculations in Microsoft Excel. All lengths and areas were calculated using XTools Pro 3.1.1 table operations tools. Active channel widths and areas were calculated by subtracting the island measurements from the channel measurements. The entire process, including clipping the cross sections by the channel and island polygons, should be amenable to automation with a Visual Basic for Applications script.

\section{Erosion areas}

After overlaying the banks from each set of photographs, the total channel width data were used to identify areas of active bank erosion within the study reach (width change from 1992 to $2006>5 \mathrm{~m}$ ). Originally, the relative bank positions at these locations were compared and erosion areas relative to the 1985 bank lines were digitized in ArcGIS 9.1 at a set scale of 1:1500. Areas were selected if the banks seemed to be clearly retreating from the oldest banks to the youngest. An alternative method was used later, where a spatial overlay was performed in the GIS with ET Geowizard 9.6's geoprocessing tools to isolate areas that fell outside the 1985 channel polygon. This method allows for faster processing but less control over the area delineation. It also seemed to increase the error associated with the measurements.

\section{Error}

Although the sources, types, and implications of error associated with spatial data are relatively well known (e.g., Leung and Yan 1998; Hughes et al. 2006), river scientists often ignore this error when analyzing geomorphic change, or rely only on the root-mean-square error of the base layer (Hughes et al. 2006). Because of the large error likely associated with measuring channel change from aerial photographs, an attempt was made to define the error in the width, area, and rate of change calculations.

A histogram of the differences between the 1992 and 2006 total channel widths indicate a wide range in values; however, the larger magnitude changes match observations from the images (Figure 2). Repeat measurements in stable reaches indicate that operator error results in width errors between $13 \mathrm{~m}$ on the 1985 photographs and $2.5 \mathrm{~m}$ on the 1999, 2002, and 2004 photographs. The average error for repeat measurements for all the images is $5 \mathrm{~m}$. In the final width data, there is less than a $5 \mathrm{~m}$ difference between total channel widths in 84 percent of the cross sections, and observations of channel widths at random cross 
sections along the study reach indicate that where differences in width are higher, the channel is adjusting. Delineating islands was somewhat more problematic, and error in island width was increased to $\pm 8 \mathrm{~m}$.

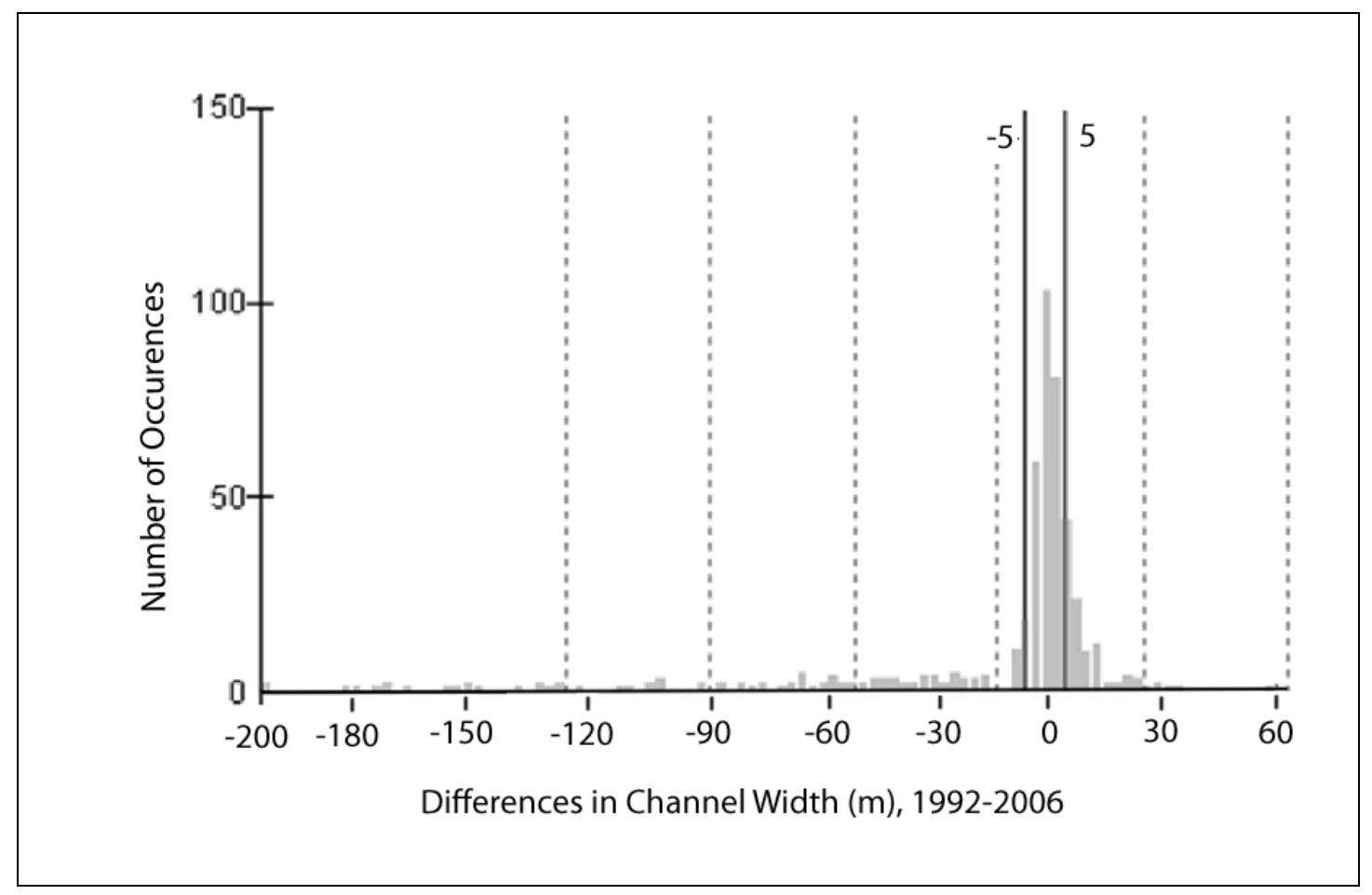

Figure 2. Histogram of differences between the 1992 and 2006 total channel widths (m). Positive numbers indicate channel widening and negative numbers indicate narrowing. The dotted gray lines represent standard deviations and the blue lines represent error.

For error associated with polygon area, two critical assumptions were made: (1) the width errors are the error in any direction (length and width), and (2) the polygons representing these areas are rectangular. Error for rectangular area can be found with the following equation (Taylor 1982):

$$
\mathrm{A}_{\mathrm{e}}=\sqrt{(\Delta \mathrm{L} / \mathrm{L})^{2}+(\Delta \mathrm{w} / \mathrm{w})^{2}}
$$

where

$$
\begin{aligned}
\mathrm{A}_{\mathrm{e}} & =\text { Fractional error in erosion area } \\
\Delta \mathrm{L} & =\text { error in length } \\
\mathrm{L} & =\text { length } \\
\Delta \mathrm{W} & =\text { error in width } \\
\mathrm{W} & =\text { width }
\end{aligned}
$$


In the preceding equation, as the length increases, $\Delta \mathrm{L} / \mathrm{L}$ approaches 0 ; therefore, assuming a high length:width ratio, $\Delta \mathrm{L} / \mathrm{L}$ becomes insignificant and the error equation becomes $\mathrm{A}_{\mathrm{e}}=\Delta \mathrm{w} / \mathrm{w}$.

Of course, channels and other natural river features are not actually rectangular. Widths vary across the channel in both space and time, with length-to-width ratios in the study reach varying from 157:1 to 180:1, with a mean of approximately 170:1. To find the relationship between width and area in rectangles with the mean length-to-width ratio, areas were calculated using theoretical pairs of length and width values, with each pair possessing this ratio (170:1). A power curve was fit to a plot of the theoretical widths versus the calculated areas, with a resulting equation of $\mathrm{w}=0.0756 \mathrm{~A}^{0.5}$, where $\mathrm{w}=$ representative width, and $\mathrm{A}=$ Area. This equation was then used to calculate the representative widths of the areas (average width assuming a length:width ratio of 170:1) measured on the aerial photographs. The final error for each area was calculated by dividing the estimated channel width error $( \pm 5 \mathrm{~m})$ by its representative width $\left(\mathrm{w}=0.0756 \mathrm{~A}^{0.5}\right)$. Using this method results in higher errors for smaller areas, so as the level of detection is approached for channel changes on the photographs the error increases dramatically. For channel areas in this study, the error is approximately 3 percent and for the islands it is approximately 20 percent. Error propagation was calculated using standard error analyses (e.g., Taylor 1982).

The error associated with the erosion areas was calculated using the same method. The ratio of length to width varied between 12:1 and 113:1 with a mean of approximately 60:1. Using this mean ratio, the equation for the representative width for each erosion area was $\mathrm{w}=0.1291 \mathrm{~A}^{0.5}$. The final error for each erosion area was calculated by dividing the estimated channel width error $( \pm 5 \mathrm{~m})$ by its representative width $\left(\mathrm{w}=0.1291 \mathrm{~A}^{0.5}\right)$.

\section{Results and discussion}

\section{Discharge data}

Discharge data were obtained from the USGS gage on the Rio Grande at Albuquerque, NM (site 8330000; Figure 3). Between 1972 and 1985, large flows ( $>200 \mathrm{~m}^{3} / \mathrm{sec}$ ) of relatively high duration ( $>3$ days) occurred in 5 of 13 years, including the $270 \mathrm{~m}^{3} / \mathrm{sec}$ peak flow in 1984 , the largest during the study period. High flows characterize the beginning of the 1985-1992 period, followed by a period of lower flow years between 1987 and 1992. 
The period from 1992 to 1996 is characterized by high peak flows between 175 and 205 m³/sec. The 1996 to 1999 data include a 175 m³/ sec peak, which is followed by a moderate peak in 1999 and drought conditions from 2000 through 2003, with one relatively brief moderate peak in 2001 . The 2004 to 2005 photograph year is defined by a peak discharge of approximately $190 \mathrm{~m}^{3} / \mathrm{sec}$, and the 2005-2006 period includes the tail end of that flood followed by low flow conditions.

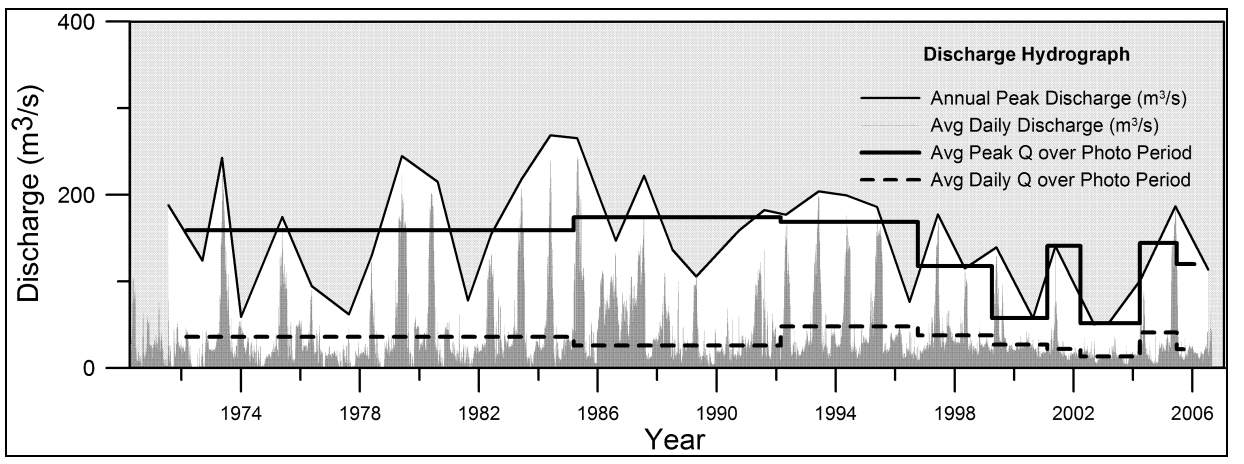

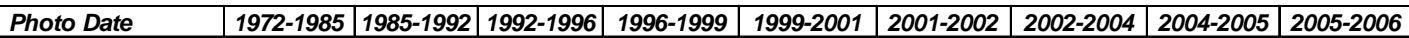

\begin{tabular}{|c|c|c|c|c|c|c|c|c|c|}
\hline Mean Peak Flow $\left(\mathrm{m}^{3} / \mathrm{s}\right)$ & 159 & 174 & 169 & 118 & 58 & 141 & 52 & 144 & 120 \\
\hline Mean Avg Daily Flow $\left(\mathrm{m}^{3} / \mathrm{s}\right)$ & 36 & 26 & 48 & 38 & 27 & 22 & 13 & 41 & 22 \\
\hline
\end{tabular}

Figure 3. Hydrograph from the USGS Rio Grande at Albuquerque, NM, gage (1972-2007; site 08330000). Step plots' tread represents average discharge values between photograph periods and the riser represents photograph date, where solid line is average peak discharge between photographs and dashed line is average daily discharge between photograph periods.

\section{Channel width}

As noted by earlier researchers (e.g., Makar et al. 2006), total channel widths, which include islands within the channel cross section (Figure 4), and active channel widths, which are reduced by the width of any islands in the cross sections (Figure 5), decreased over the study period. Average active channel width diminished from $169 \pm 5 \mathrm{~m}$ in 1972 to $130 \pm 5 \mathrm{~m}$ in 2006 (Table 2). A review of the photographs indicates much of the decrease in channel widths are associated with expansion and bank attachment of vegetated islands. Although within the error, the steepest parts of the curve representing average active channel width over time (Figure 5) occur during the drought years between 1999 and 2004, and again after the flood in 2005. Likely, lower flows deposit materials along bar flanks and side channels where vegetation can establish during these periods. Also, limited peak flows over that time may not have reached a high enough stage or have enough power to remove established vegetation or seeds. The increase in bar attachment and expansion noted between the 2005 and 2006 images might relate to large amounts of fresh sediment 
deposited on bar surfaces after the 2005 flood, followed by low flows during the subsequent summer and fall; however, misinterpretation of the 2006 photographs is also a possible explanation. In addition, the standard deviation in total width, a measure of channel variability or planform heterogeneity, has also decreased over the study period.

Figures 6 and 7 indicate where changes in active channel width have occurred. Narrowing is concentrated between the North Diversion Channel and the Paseo del Norte Bridge, in the upper third of the study area (Figure 7A-G). This reach is also where most of the island activity is occurring. These adjustments might be related to upstream channel degradation associated with Cochiti Dam (MEI 2003; Richard and J ulien 2003; Ortiz 2004). Adjustment downstream of arroyo junctions is also common, especially narrowing downstream of Arroyo de las Calabacillas, which has constricted the channel by deposition of a large tributary fan (Figure 7G). Other areas of active adjustment over this time period occur immediately up and downstream of the South Diversion Channel and immediately upstream of Interstate (I-40).

One of the general observations made from the Figure 7 plots is that major changes in channel width upstream of the Southwestern Indian Polytechnic Institute (Figure 7A-H) occurred where the 1972 channel was relatively wide (>200 m) and smaller adjustments are associated with reaches where the 1972 channel was narrow $(<150 \mathrm{~m}$ ). Table 2 also shows a relatively large decrease in maximum active widths, from $345 \mathrm{~m}$ to $243 \mathrm{~m}$ between 1972 and 2006, whereas the minimum active widths remain fairly steady, from 42 to $39 \mathrm{~m}$, over the same time period. Figure 7 also indicates that the most dynamic subreaches over the last 15 years lie just up and downstream of the North Diversion Channel (Figure 7E), and directly downstream of the Isleta Diversion Dam (Figure 7S).

\section{Channel areas}

The error analysis for change detection revealed that few differences in channel change and rates of change were significant. Relatively large errors occur primarily because changes between photograph years at specific locations are often near the limits of detection, and these large error magnitudes are propagated through the rate calculations. Some of this error appears unrealistic, as many of the changes are qualitatively apparent on the air photographs. In the end, although not significant, the data does show patterns in relation to the flow data that may be informative. 


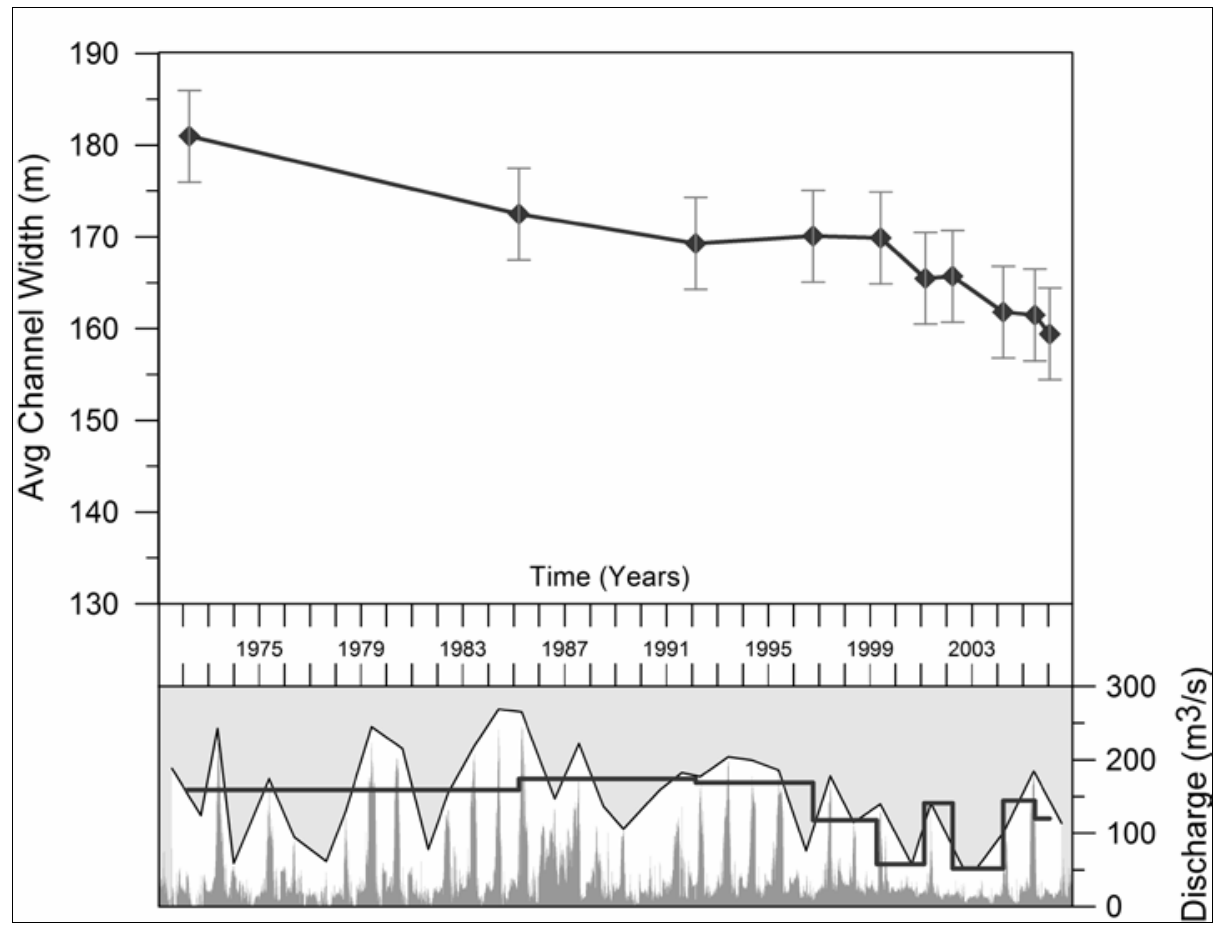

Figure 4. Change in average total channel width from 1972 to 2006. Average total channel widths decrease over study period. Discharge metrics shown as in Figure 3.

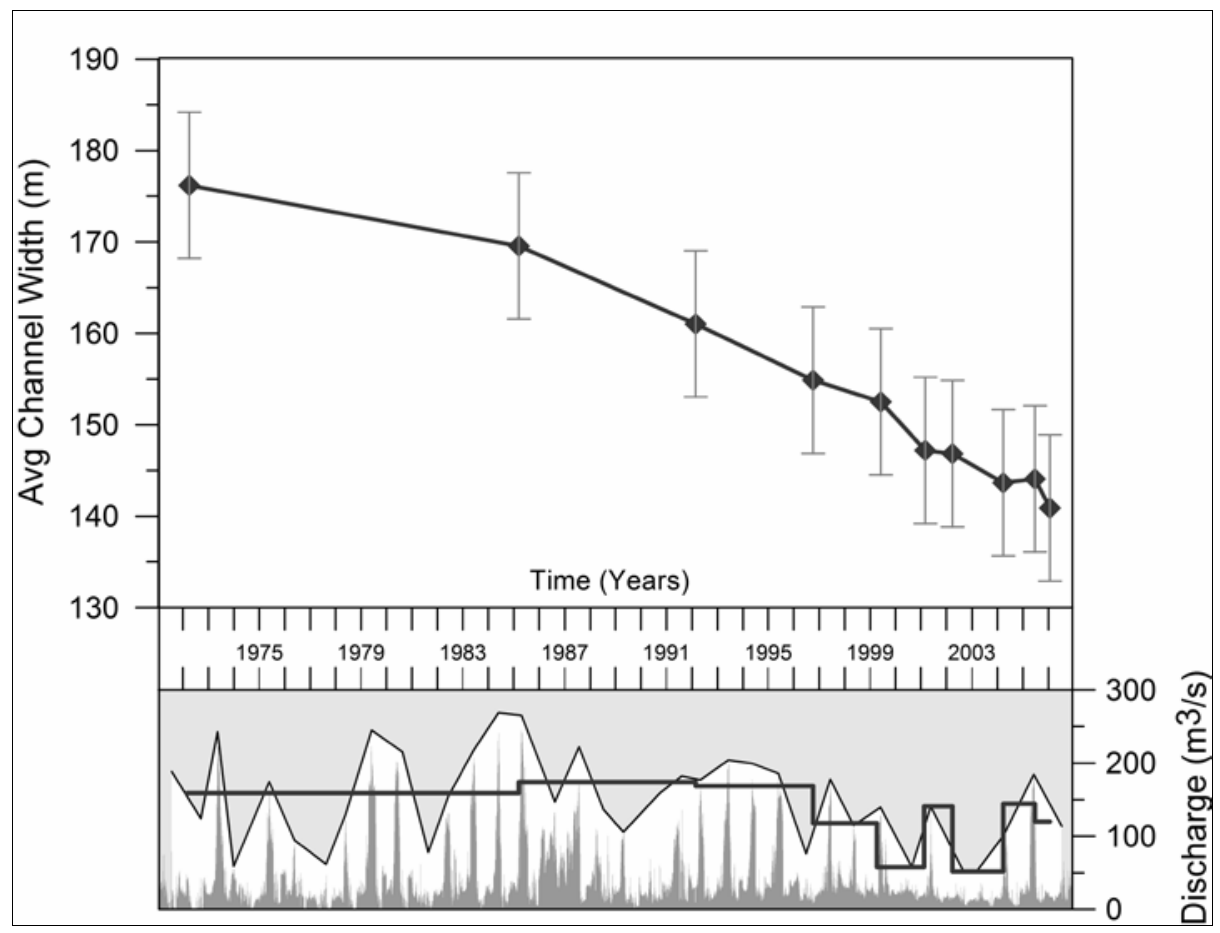

Figure 5. Change in average active channel width (excluding islands) from 1972 to 2006. Average active channel widths decrease over study period. Discharge metrics shown as in Figure 3. 
Table 2. Statistics associated with active channel widths for each photographic year, in meters.

\begin{tabular}{|l|c|c|c|c|c|c|c|c|c|c|}
\hline STATS & YR1972 & YR1985 & YR1992 & YR1996 & YR1999 & YR2001 & YR2002 & YR2004 & YR2005 & YR2006 \\
\hline \hline Mean & 169.0 & 160.0 & 161.8 & 145.2 & 148.0 & 138.1 & 141.3 & 137.3 & 134.9 & 130.1 \\
\hline Stand. Dev. & 54.2 & 46.1 & 45.0 & 37.9 & 39.4 & 38.0 & 39.2 & 39.2 & 39.1 & 38.8 \\
\hline Max & 345.3 & 316.8 & 306.1 & 266.3 & 265.8 & 243.3 & 280.3 & 244.0 & 246.5 & 243.3 \\
\hline Min & 41.7 & 42.2 & 38.9 & 49.8 & 43.0 & 36.9 & 42.3 & 42.9 & 40.2 & 38.9 \\
\hline
\end{tabular}

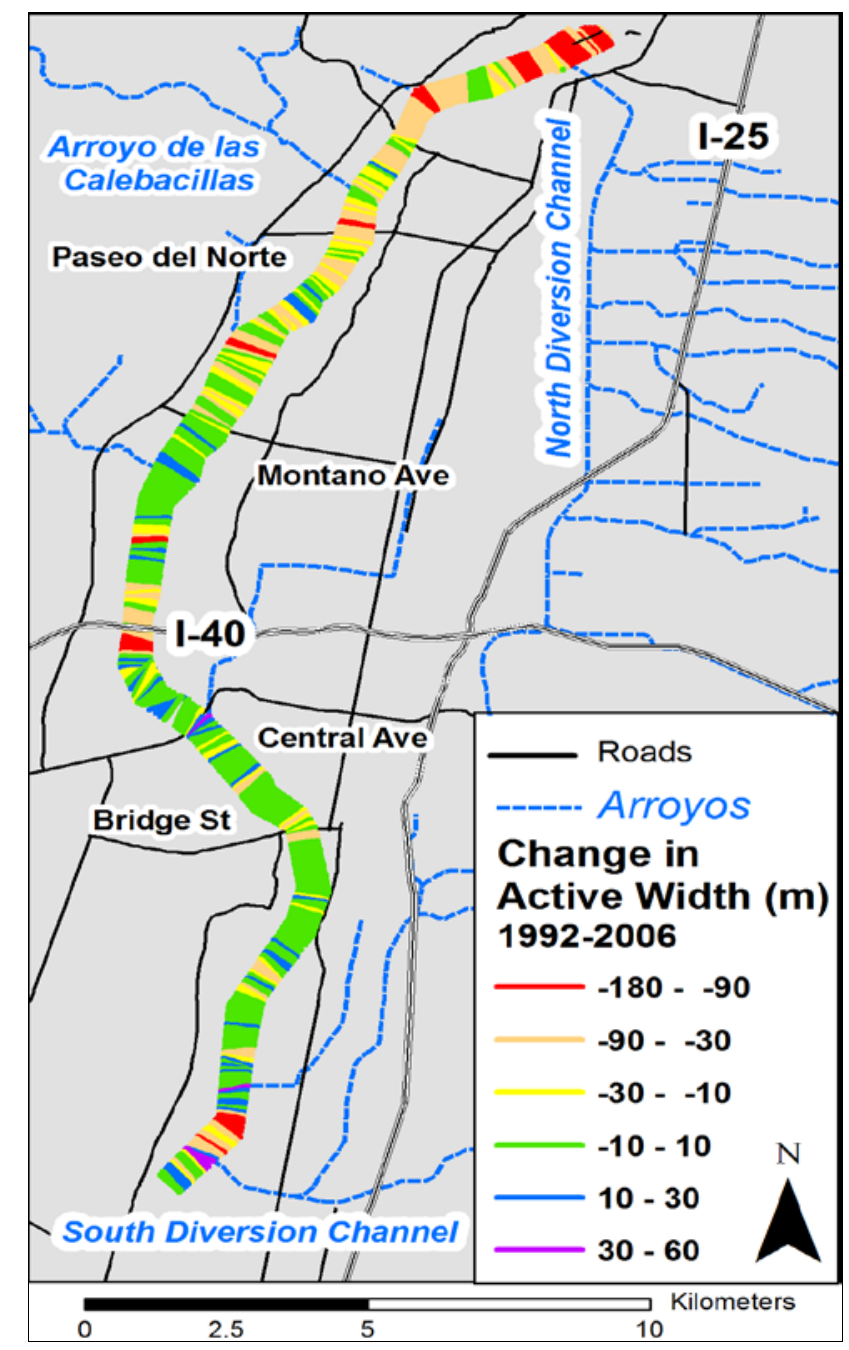

Figure 6. Channel change locations from 1992 to 2006. Warm colors (red, orange) indicate areas where channel is narrowing (bar attachment and expansion) and cool colors (violet, blue) indicate widening (bank erosion). Channel has narrowed in upper third (North AMAFCA Diversion Channel to Paseo del Norte), middle (above I-40), and downstream end (South AMAFCA Diversion Channel) of study reach. 


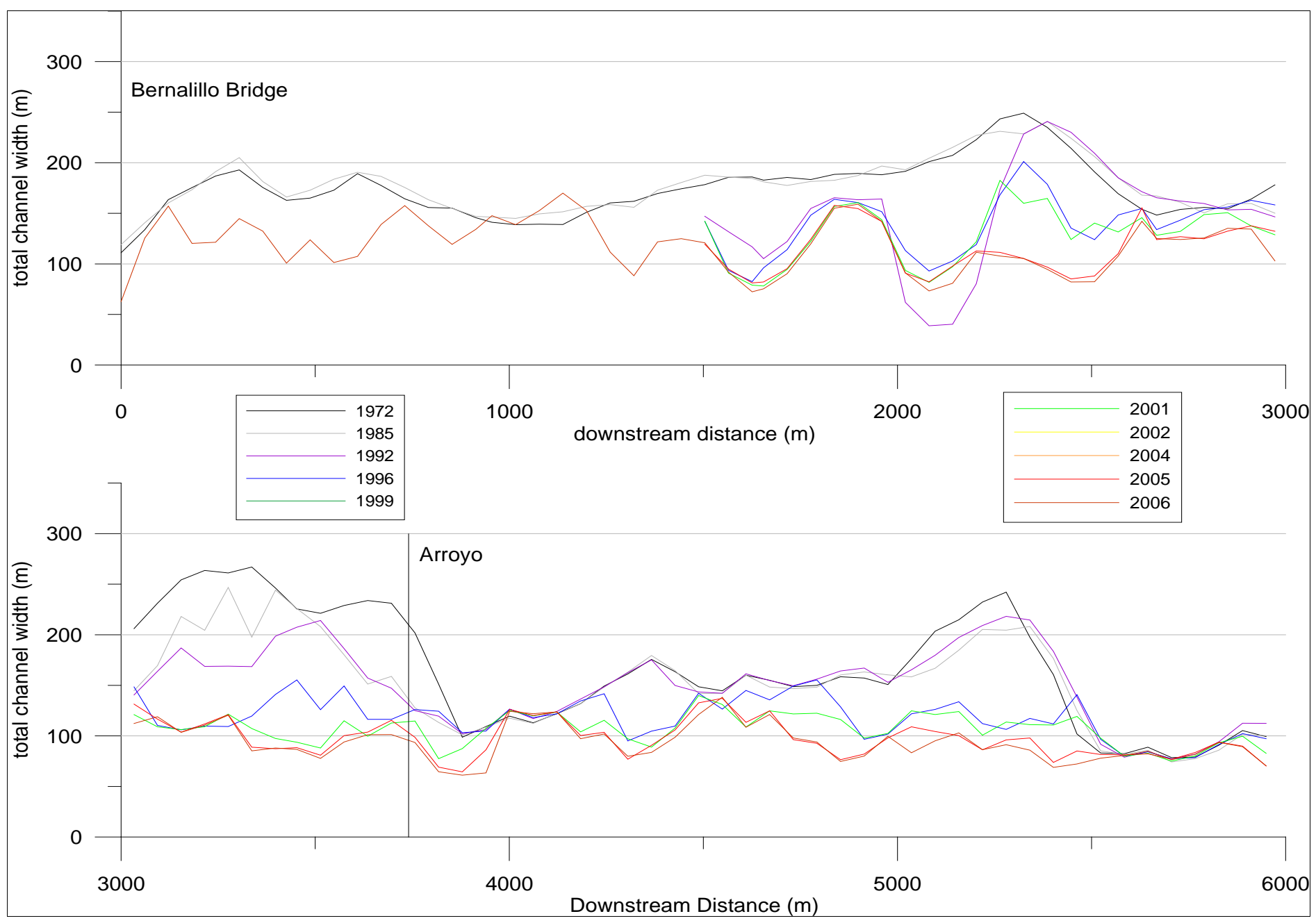

Figure 7A (top) and 7B (bottom). Change in active channel width downstream of Bernalillo Bridge. 


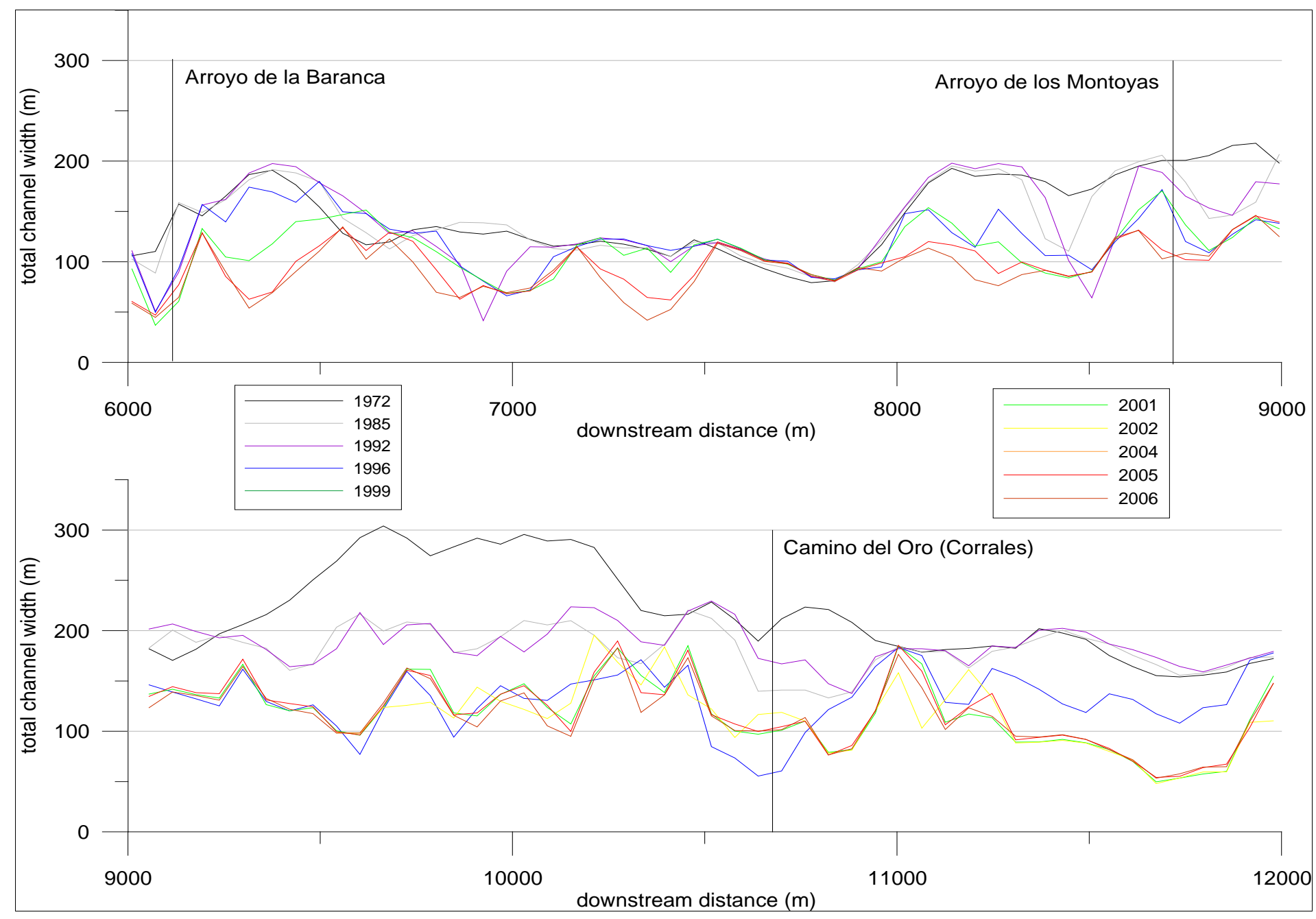

Figure 7C (top) and 7D (bottom). Change in active channel width from Arroyo de la Baranca through Corrales. 


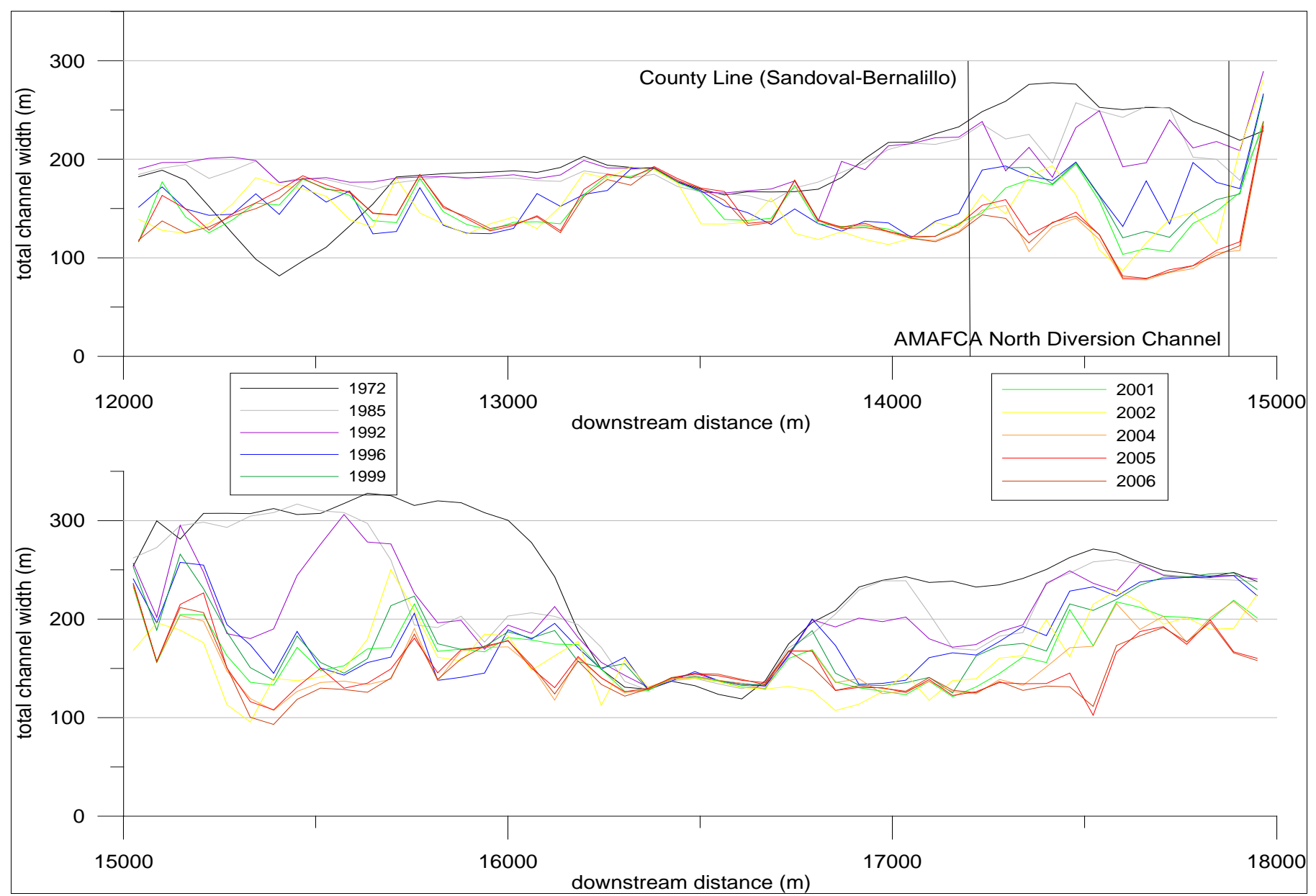

Figure 7E (top) and 7F (bottom). Change in active channel width from Corrales to below the North Diversion Channel. Channel narrowing up and downstream of diversion channel has been relatively active in last 10 years. 


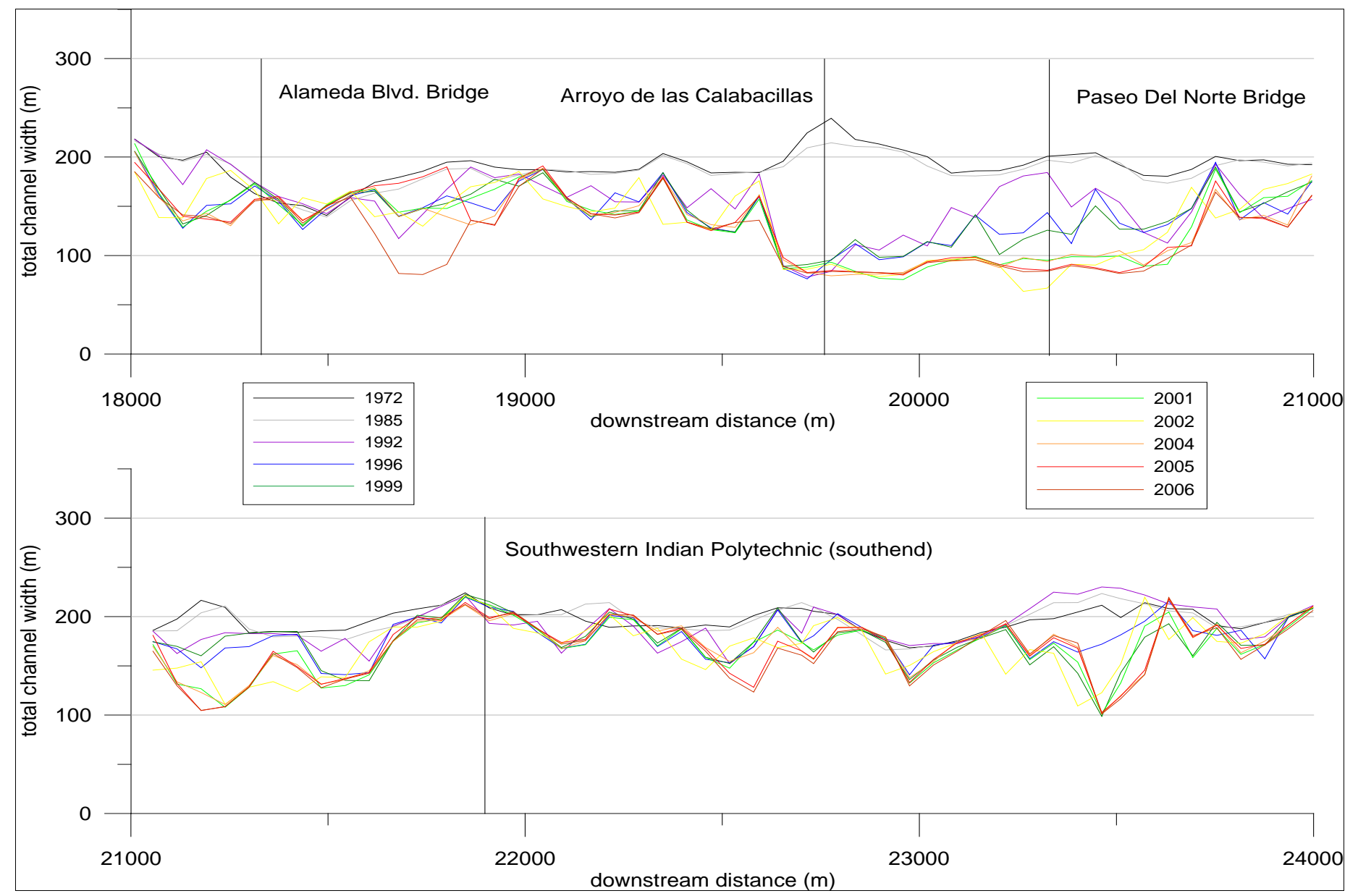

Figure $7 \mathrm{G}$ (top) and $7 \mathrm{H}$ (bottom). Change in active channel width from Alameda Bridge to $1,000 \mathrm{~m}$ upstream of Montano Bridge. Sediment from Arroyo de las Calabacillas contributes to narrowing near and downstream of arroyo. 


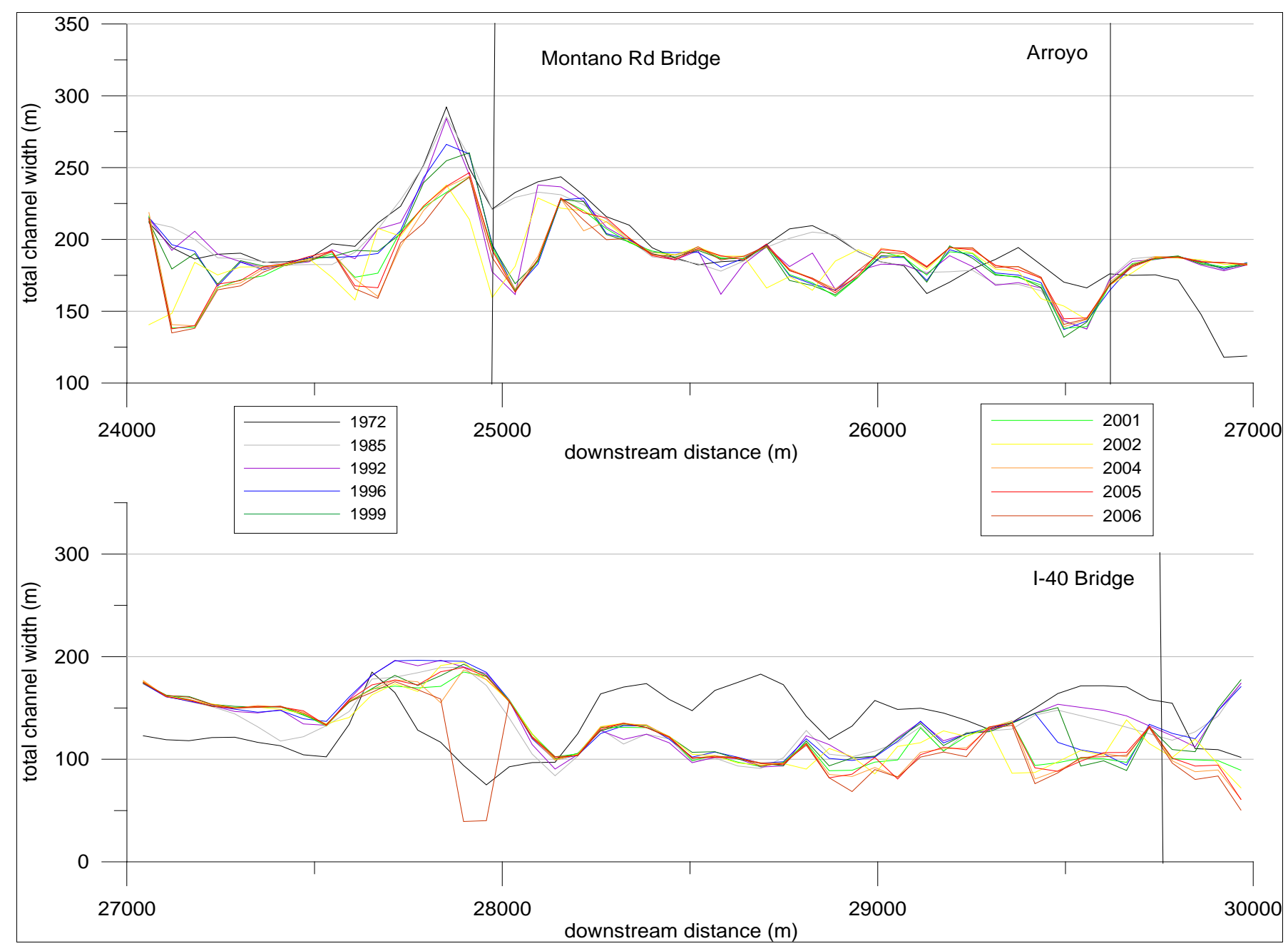

Figure $7 \mathrm{I}$ (top) and $7 \mathrm{~J}$ (bottom). Change in active channel width from Montano Bridge to I-40. 


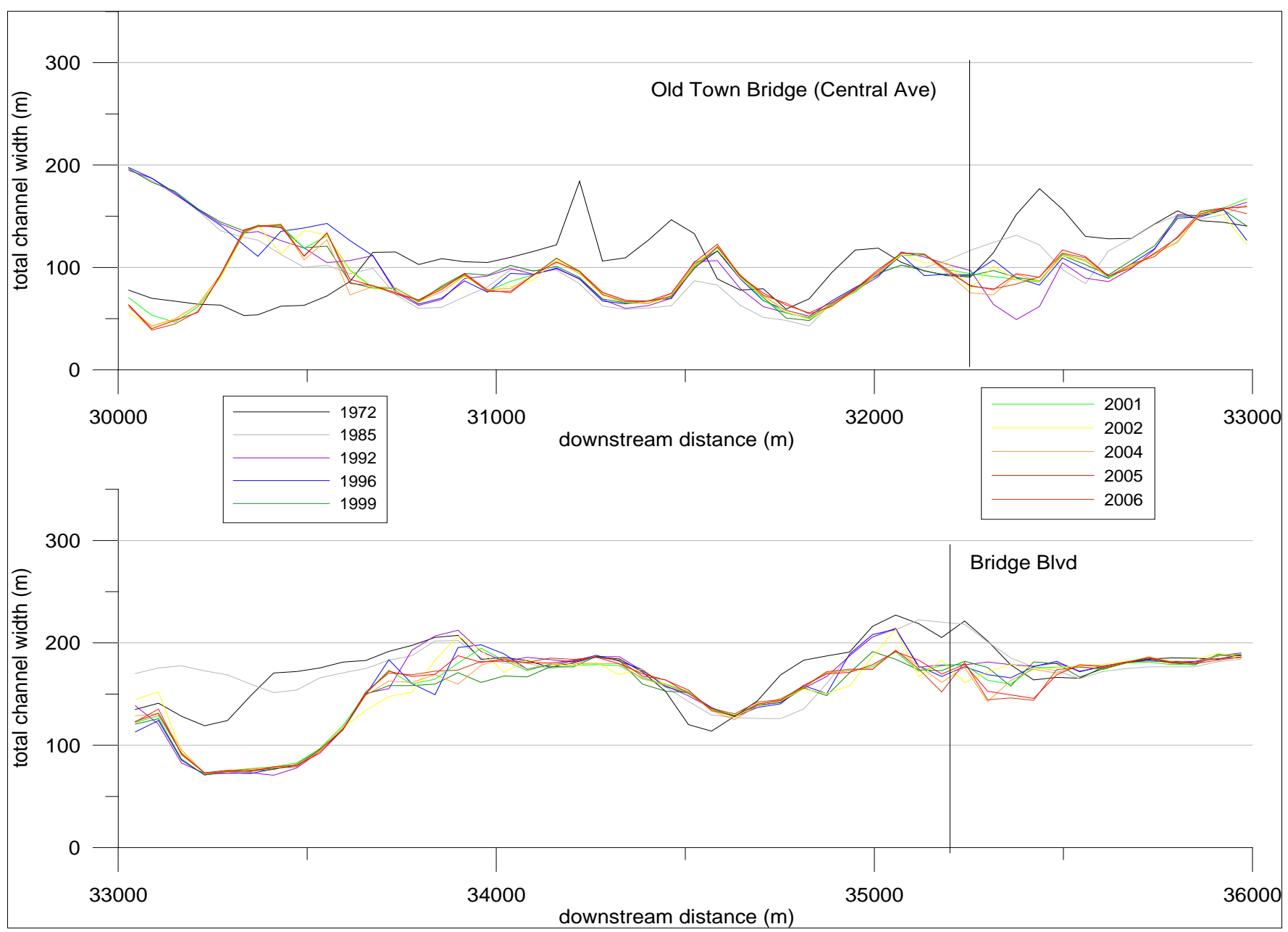

Figure 7K (top) and 7L (bottom). Change in active channel width through Old Town area to Bridge Boulevard. This reach appears relatively stable. 


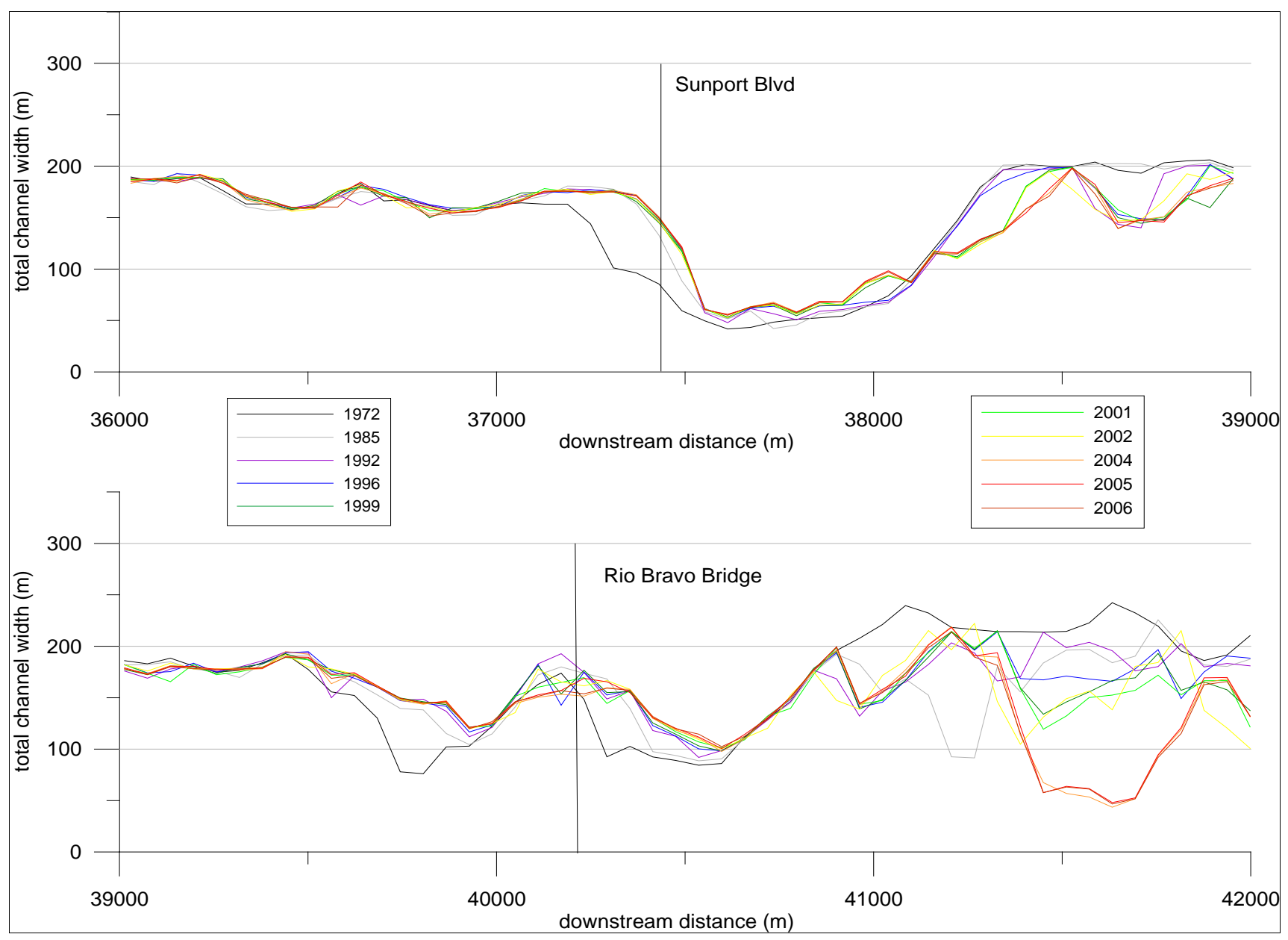

Figure $7 \mathrm{M}$ (top) and $7 \mathrm{~N}$ (bottom). Change in active channel width from downstream of Bridge Boulevard to South Diversion Channel. Channel widths are relatively stable to below Rio Bravo Bridge, but narrowing has occurred above diversion channel. 


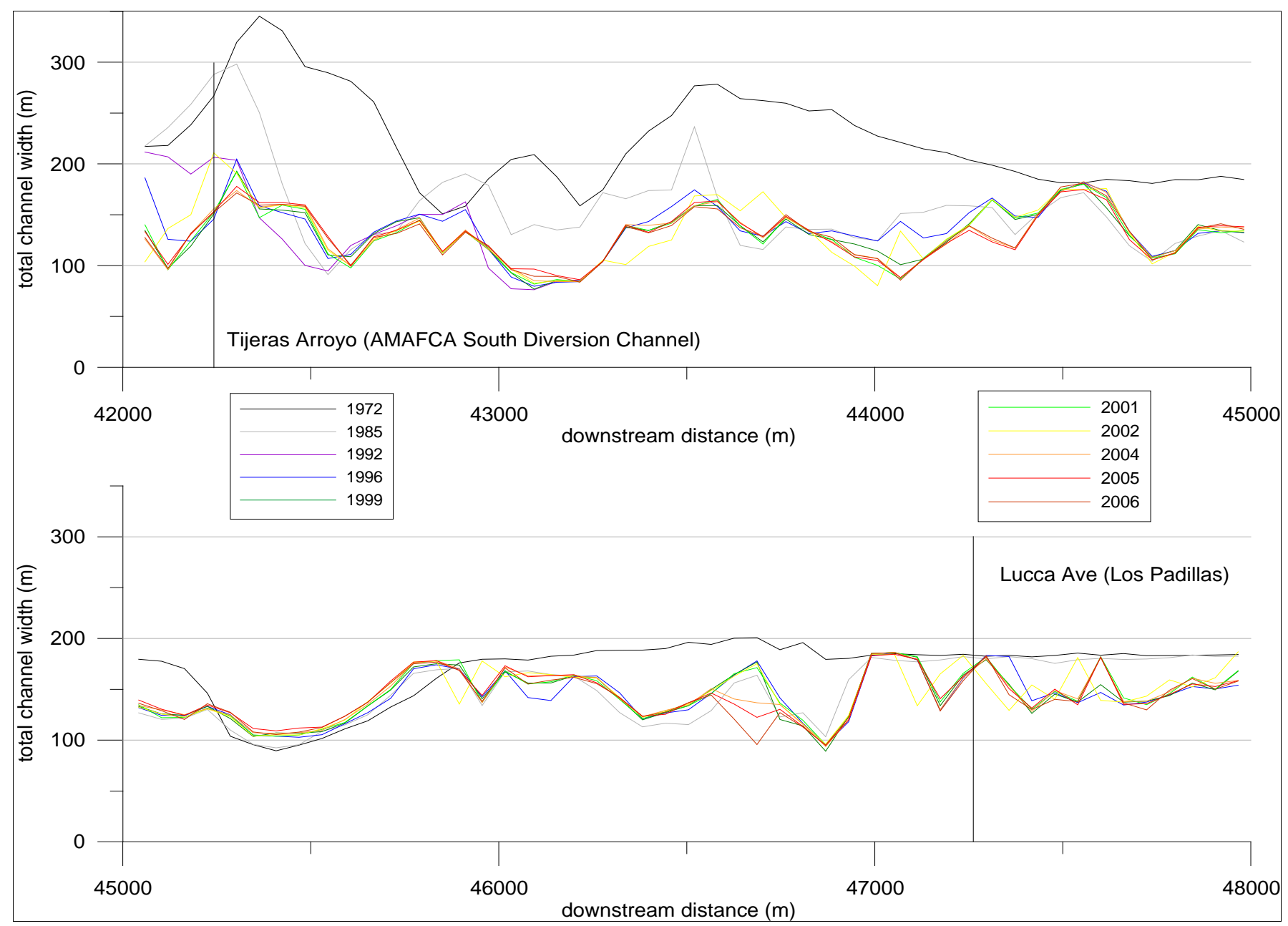

Figure 70 (top) and 7P (bottom). Change in active channel width from South AMAFCA Diversion Channel to Los Padillas. 


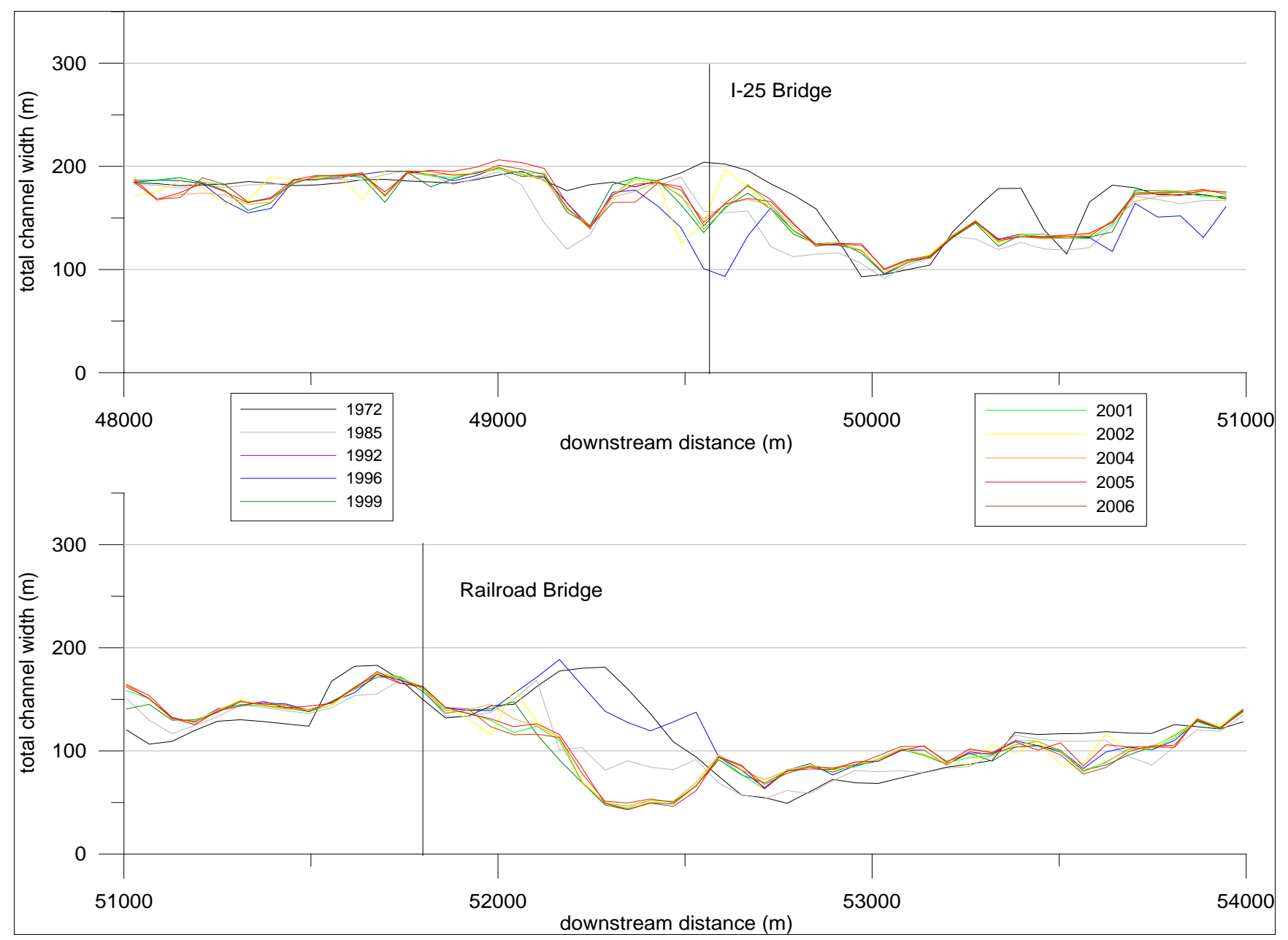

Figure 7Q (top) and 7R (bottom). Change in active channel width from Los Padillas to Isleta Diversion Dam. 


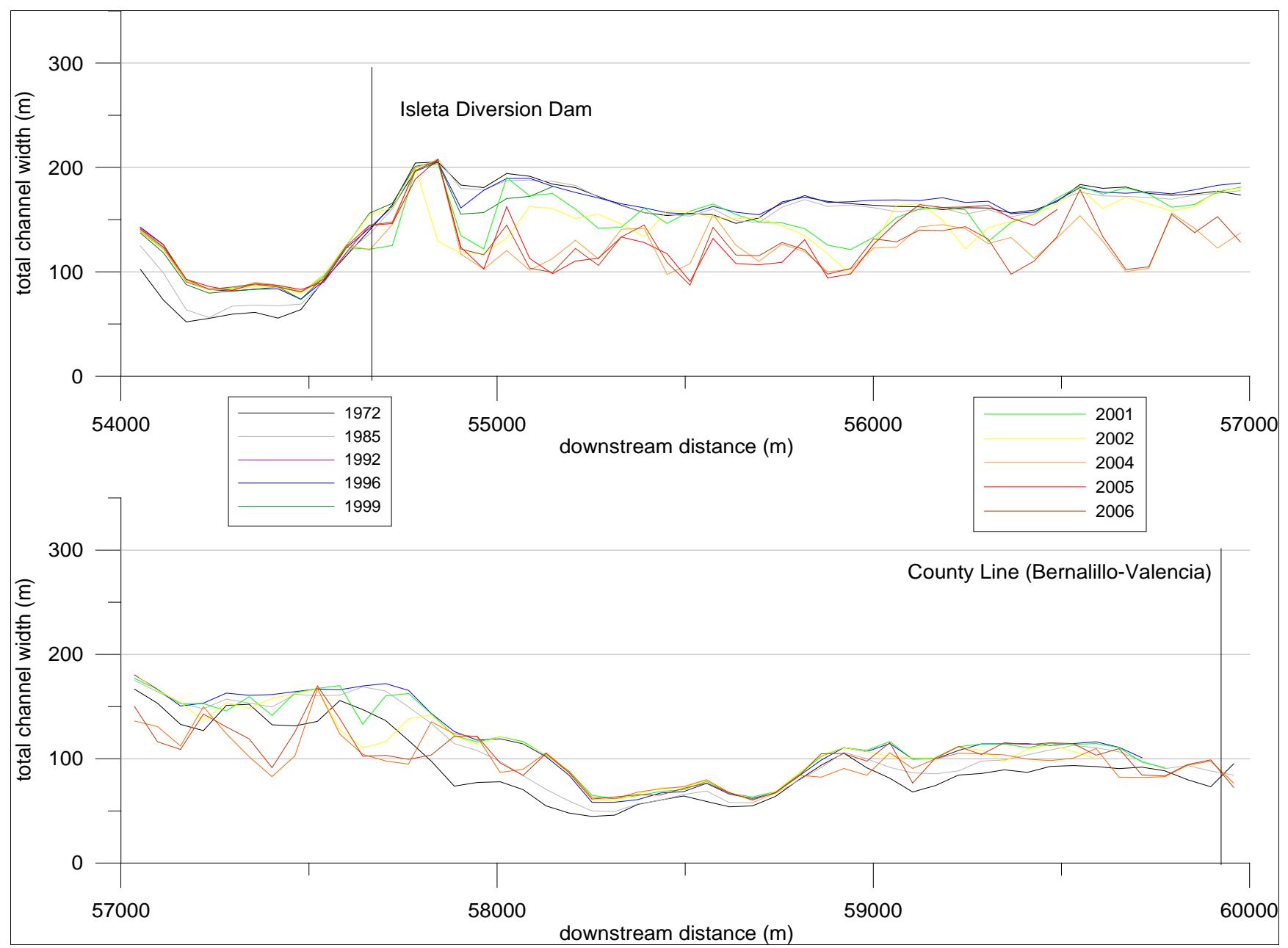

Figure 7S (top) and 7T (bottom). Change in active channel width from Isleta Diversion Dam to Bernalillo-Valencia County Line. 
Total channel area (including islands) and active channel area (excluding islands) are similar (Figures 8 and 9), and related to the change in channel widths. From 1972 to 1992, the active channel area decreased from approximately $5.2 \mathrm{~km}^{2}$ ( \pm 5 percent) to $4.2 \mathrm{~km}^{2}$ ( \pm 5 percent), and continued to decrease to $4.0 \mathrm{~km}^{2}$ ( \pm 5 percent) by the winter of 2006 (Figure 9). Much like the width change, the steep areas of the curve coincide with periods characterized or punctuated with drought and low flows, although the change from one photographic set to the next is within the error.

Total and active channel change also indicate a relationship with the flow data, where periods characterized by higher average peak flows have lower rates of change than those characterized by lower average peaks (Figures 10 and 11). In fact, the rate of change steps and the average peak discharge steps have a similar shape (Figure 10). Disregarding the error, a case can be made that flows over approximately $140 \mathrm{~m}^{3} / \mathrm{sec}(5,000 \mathrm{ft} 3 / \mathrm{sec})$ help maintain the channel, although they do not necessarily widen it, whereas the channel narrows over periods with no peaks above $140 \mathrm{~m}^{3} / \mathrm{sec}$. This discharge is similar to bank-full estimates provided by MEI (2003).

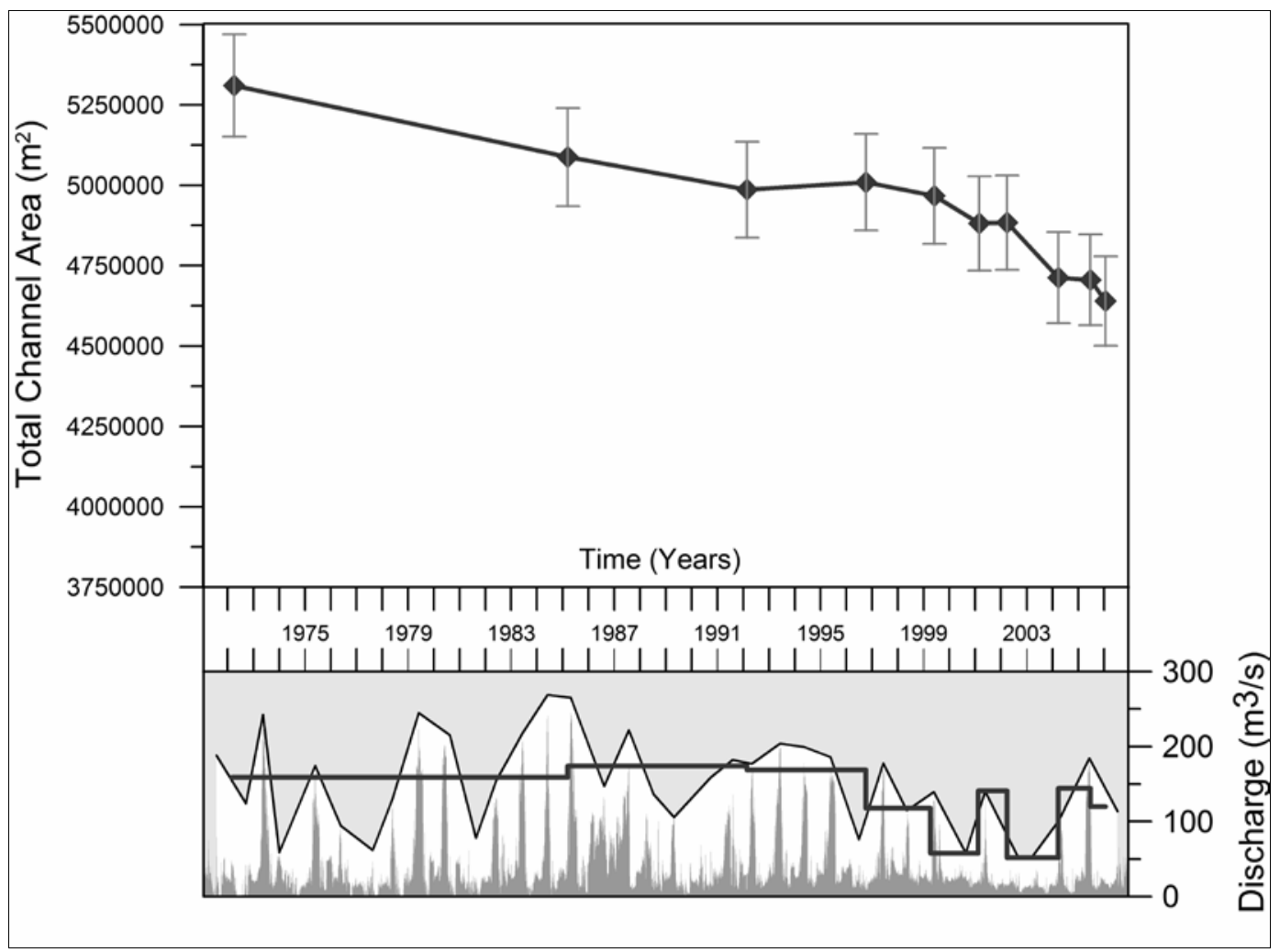

Figure 8. Change in total channel area (including island area) over time. Error is \pm 3 percent. Discharge metrics shown as in Figure 3. 


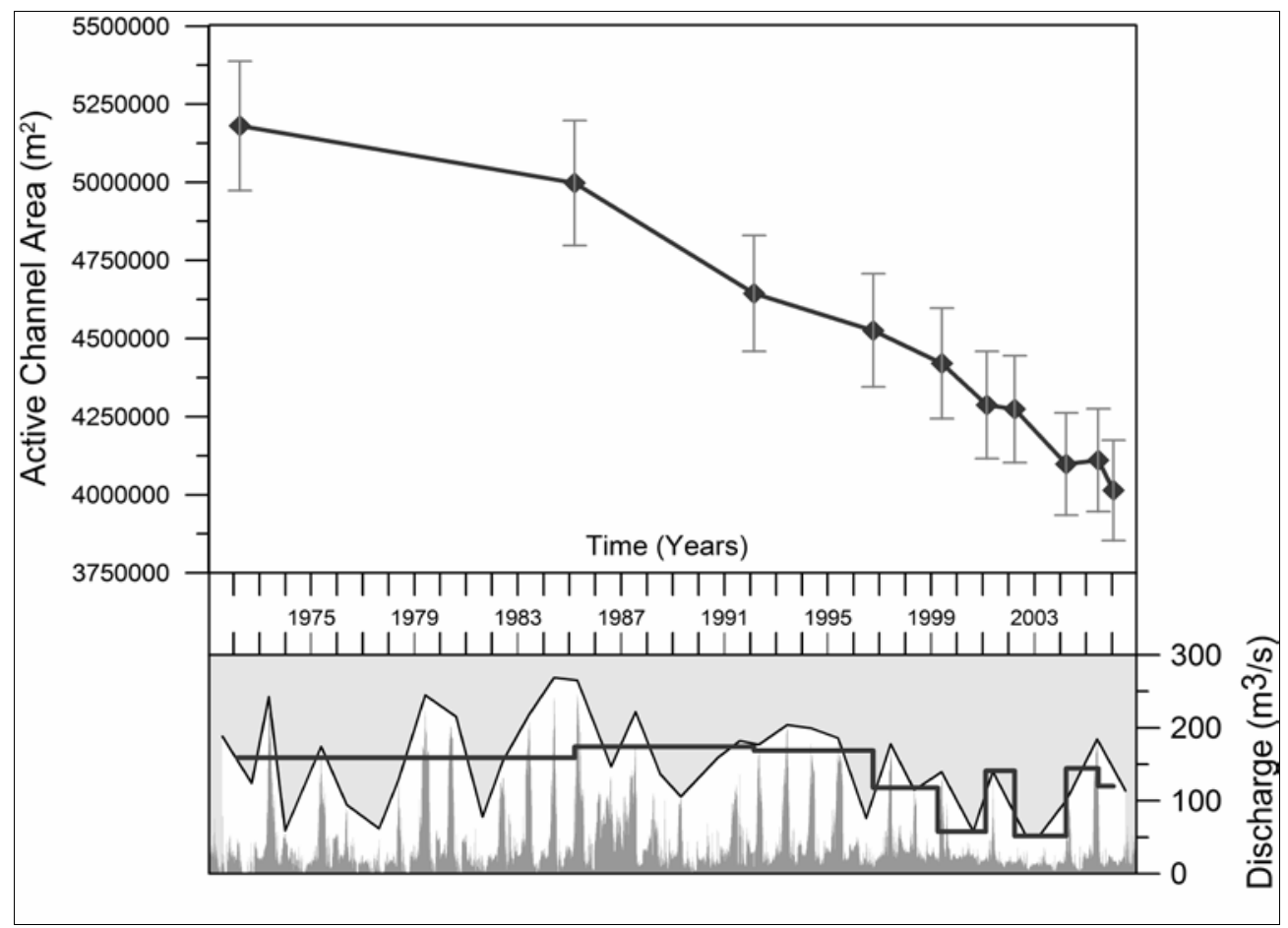

Figure 9. Change in active channel area (excluding island area) over time. Total channel area decreases over study period. Error varies from 3 to 5 percent. Discharge metrics as in Figure 3.

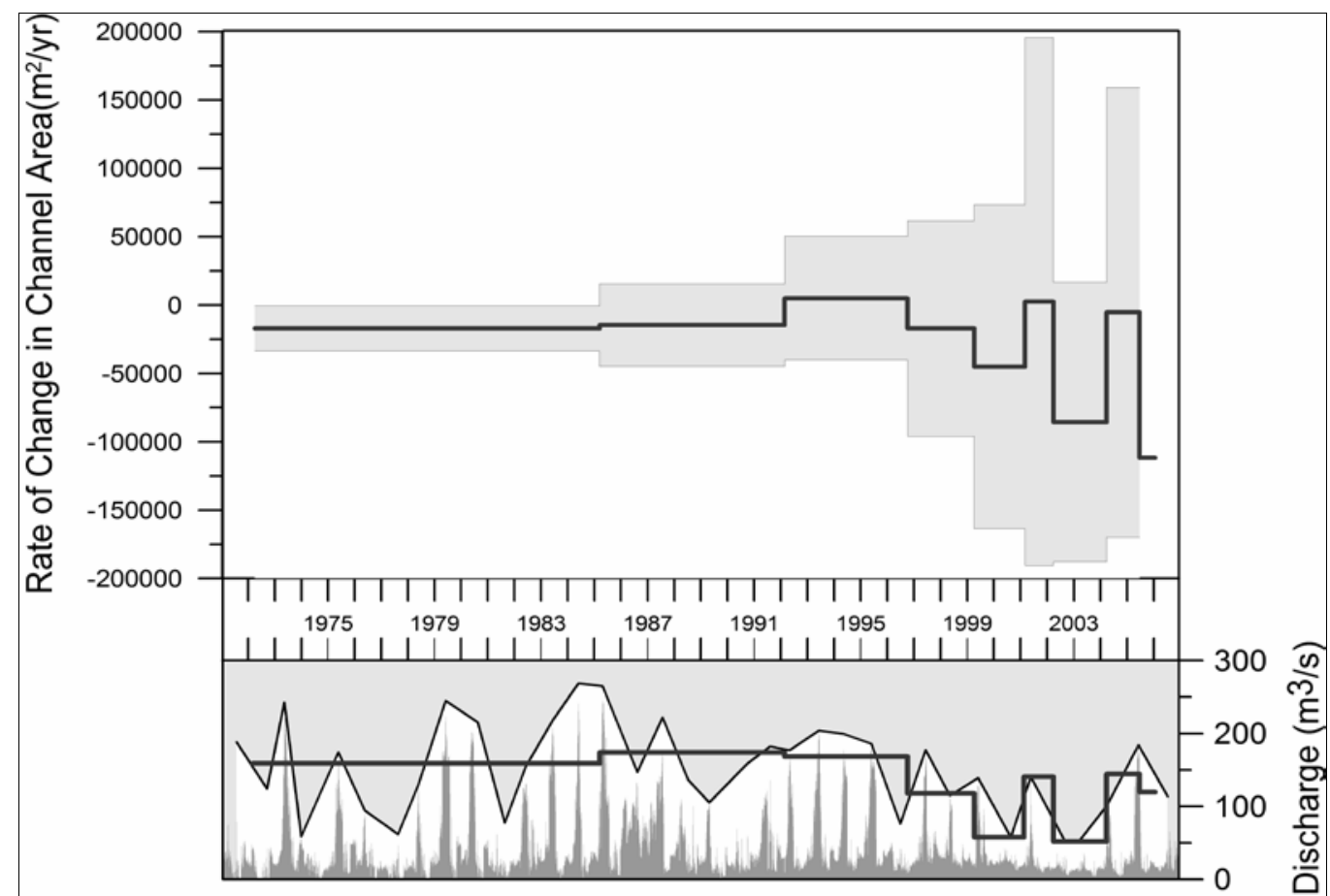

Figure 10. Rate of change in total channel area (including island area) between photograph years. Negative values indicate channel contraction. Although within the error (gray), the steps in both change in area rates and average peak discharge (red) are similar. Higher peak discharges appear to maintain channel area, whereas lower flows result in contracting. Discharge metrics shown as in Figure 3. 


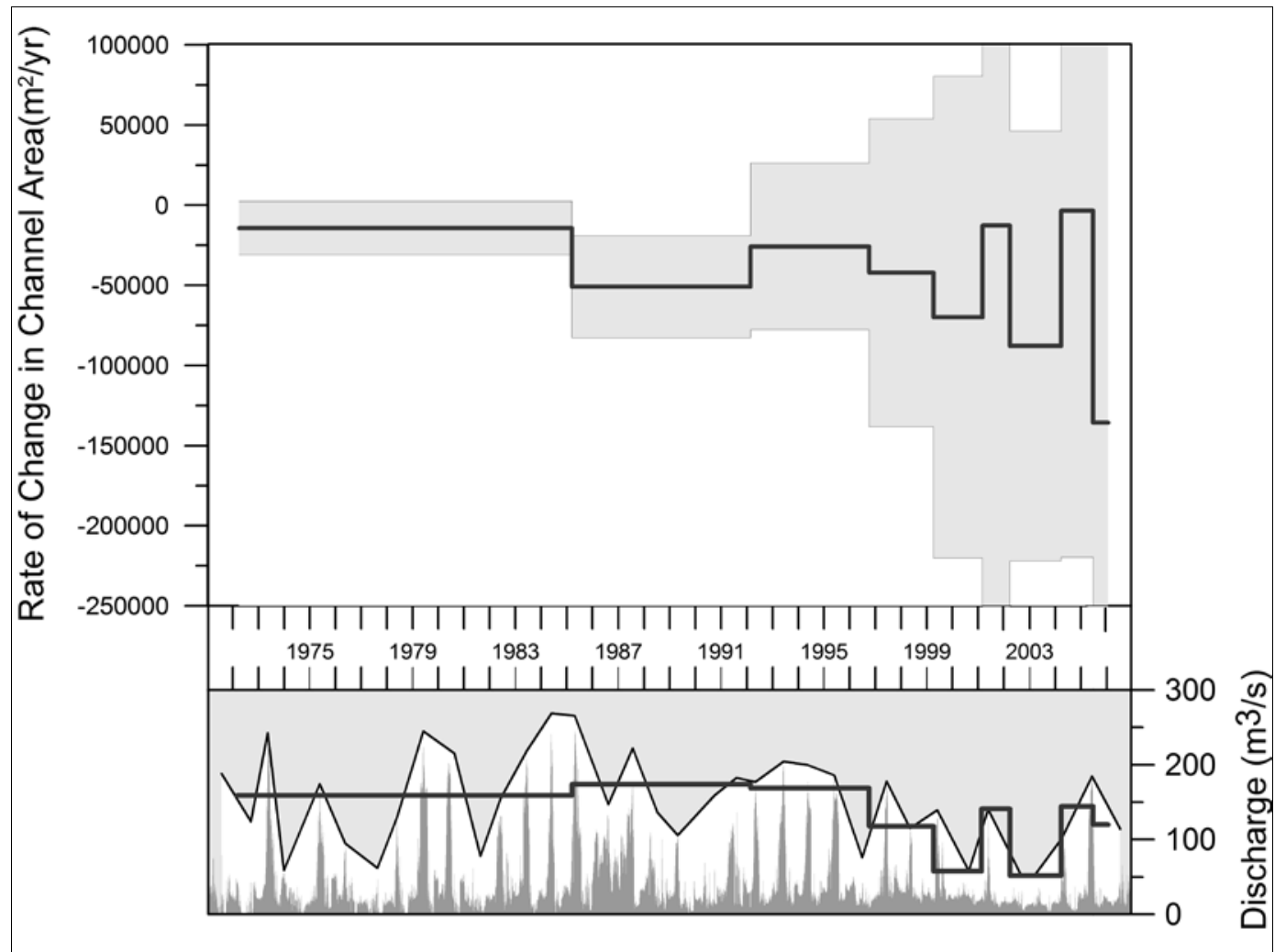

Figure 11. Rate of change in active channel area (excluding island area) between photograph years. Negative values indicate channel contraction. Although within the error (gray), the steps in both change in area rates and average peak discharge (red) are similar. Discharge metrics as in Figure 3.

As noted by others (Ortiz 2004; MEI 2006; Meyer and Hepler 2007), island area has increased over time within the study reach, from $0.15 \mathrm{~km}^{2}$ ( \pm 20 percent) to $0.65 \mathrm{~km}^{2}$ between 1972 and 2006 (Figure 12). Considering error of \pm 20 percent, it appears that the increase in island area levels off after 2001. In addition, rates of island development and expansion, also completely within the error, are relatively high between 1985 and 2002; however, the rate appears to decrease during the recent drought and the 2005 flood (Figure 13). The slower rate of island growth after 1999 (the "plateau" in Figure 12 and Figure 13) is in part due to loss of area through bank attachment during the dry years, as can be observed on the imagery. In addition, the photographs indicate that 1985 to 1996, a period characterized by steadily increasing island area, was likely a time of island development and expansion prior to relatively large scale attachment. Finally, it appears that the peak flows in the mid-1980s may have eroded some of the developing islands in the channel prior to 1985. As mentioned earlier, all of these observations are contingent on disregarding much of the substantial calculated error. 
Attached islands were not included in the island analyses, resulting in "missing" islands and abrupt decreases in channel widths and area. Future work should group these attached areas with the islands, or probably most appropriately, treat them as a third category. This categorization would allow differentiation of channel erosion versus channel narrowing by using channel area and bar expansion data, respectively.

\section{Bank erosion}

Because the spatial analysis included long, thin areas of bank erosion that would not have likely been digitized by hand, the overall erosion data also had a large amount of error. The error is not shown in the subsequent figures for the sake of clarity, and many of the longer, thinner erosion areas where erosion was not obvious between photograph sets were removed to reduce some of the error. Regardless, the error is still often greater than 500 percent of the rates presented here, so more than the previous analyses, any conclusions regarding rate changes are suspect.

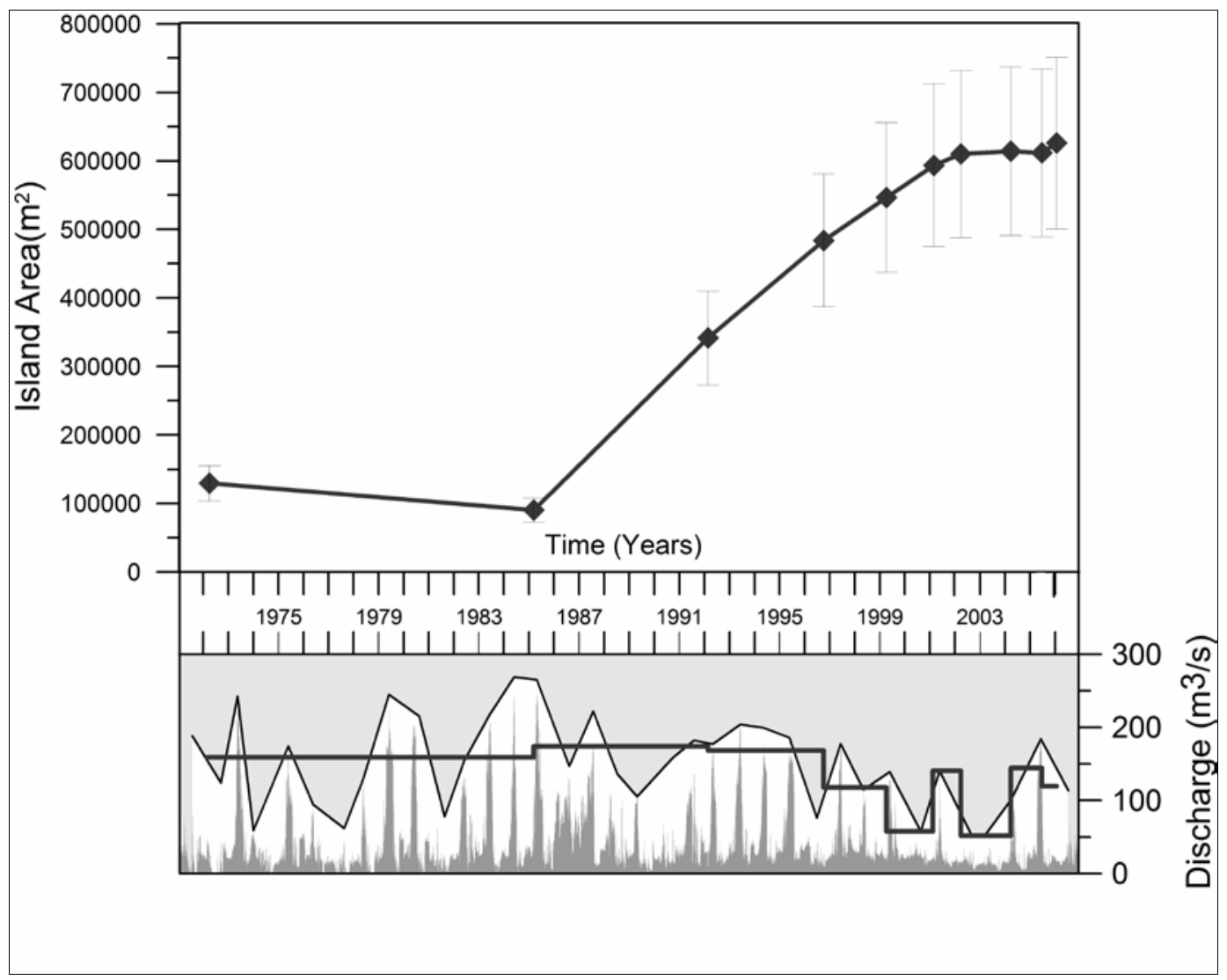

Figure 12. Change in island area over time. Island area has increased steadily since 1985. The "plateau" from 2002 to 2006 is in part due to island attachment to banks, removing island area. Discharge metrics as in Figure 3. 


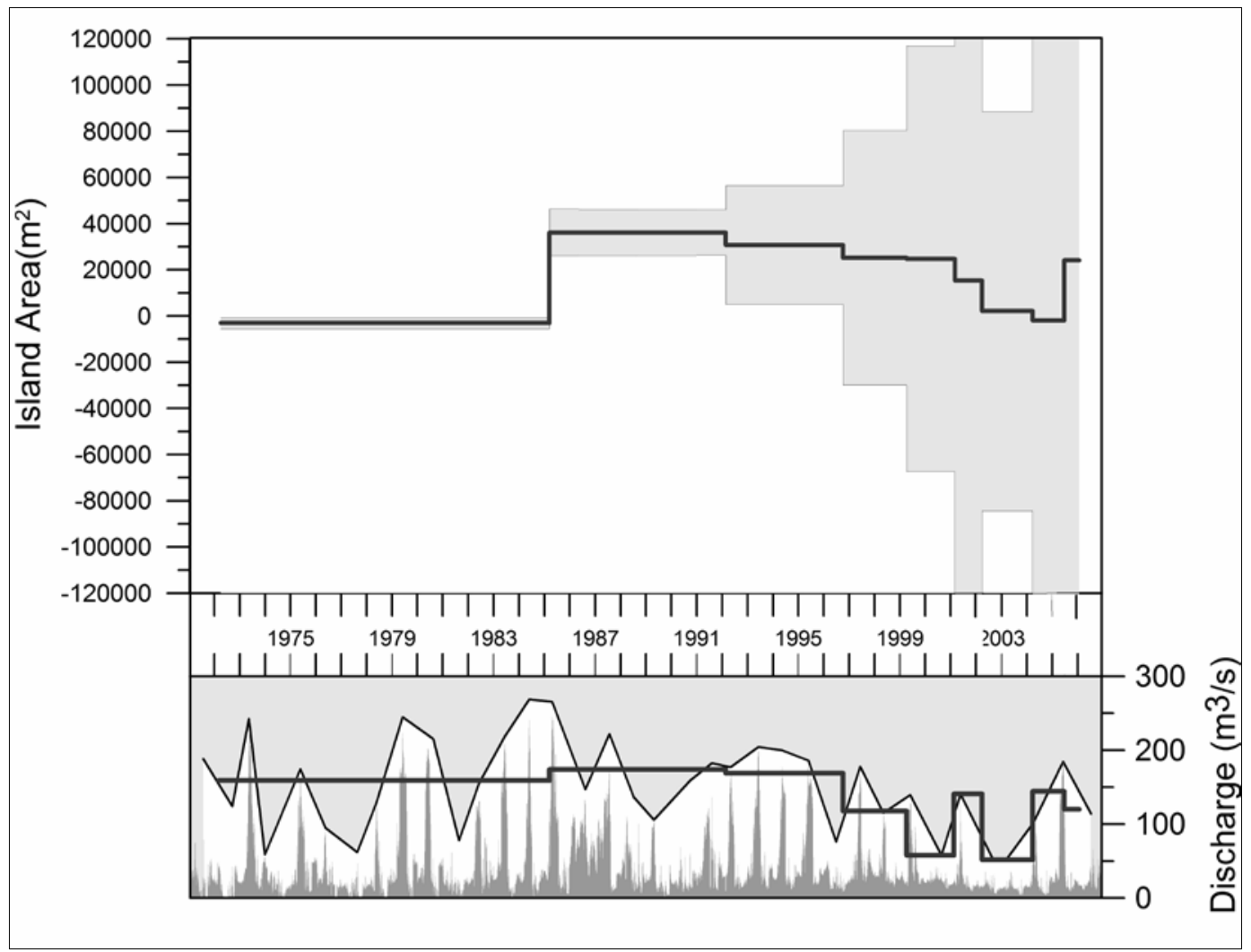

Figure 13. Rates of change in island area between photograph years. Although within the error (gray), rates of island development and expansion are relatively high between 1985 and 2002. Area (red) appears to decrease during recent drought and 2005 flood, in part due to loss of area through bank attachment during dry years. Discharge metrics shown as in Figure 3.

The rate of total bank erosion between photograph sets indicates that erosion slowed with decreasing peak discharges between 1996 and 2001, and may have even decreased despite the moderate, but brief, peak discharge in 2001 (Figure 14). Erosion rates may have then increased through both the drought years, 2002-2004, and the peak flow in 2005. It is not clear what would have led to increased erosion during the low flow years, and this relatively small change may be associated with the error. If real, it may be associated with channel narrowing and bar and island stabilization that locally has concentrated and directed flow against opposing banks. It may have taken until 2002 for enough channel narrowing to occur to force erosion at many of these sites. Also, studies along other regulated, sand-bed rivers, such as the Platte River, NB, indicate that low flow periods are often times of channel incision, or sediment reworking in the main channel, which may locally destabilize banks in narrower channels (Friedman et al. 1996). 


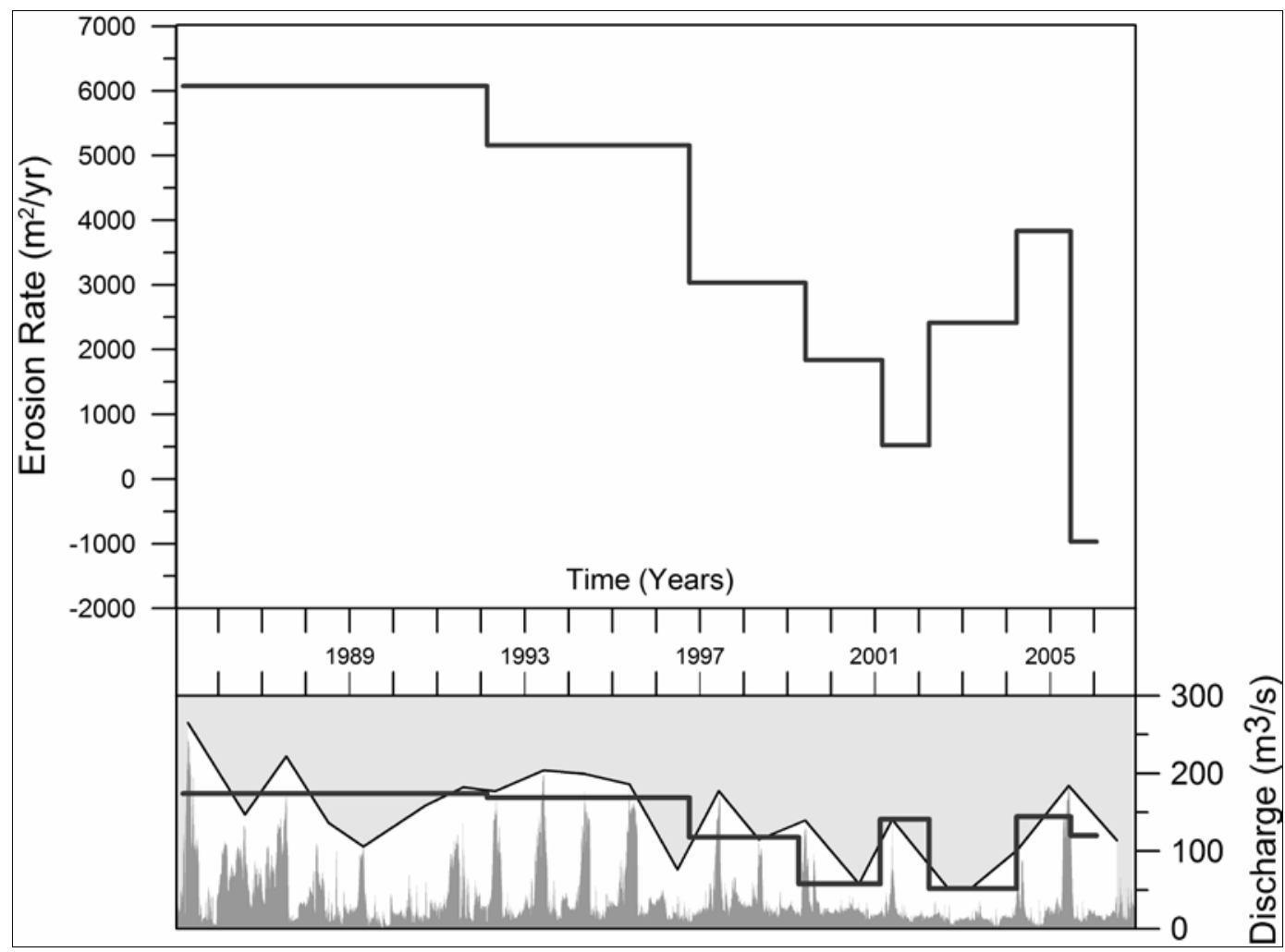

Figure 14. Erosion rates between photograph years. All values are within calculated error. Erosion rates seem to decrease through 2002, and then increase through the 2005 flood. Discharge metrics shown as in Figure 3.

Figure 15 depicts the erosion rate between 1985 and each photograph year (1985-1992, 1985-1996, 1985-1999, etc.). Under steady-state equilibrium conditions of channel change, the rate should theoretically be a relatively straight line over long periods of time. Over this relatively short period of time, the trend indicates that erosion rate is decreasing. This observation is supported by the generally stable banks observed on the images and in the field along the study area. The encroaching vegetation, bank protection, and deposition at bank toes associated with Rio Grande narrowing protect the floodplain banks from subsequent high flows, and as bars expand and attach, more bank is protected. In addition, smaller peak flows related to dam operations or multi-year droughts and related water management decisions could also lead to the decreased bank erosion.

Expanding bars do not always reduce bank erosion, however. The locations of the major erosion areas used in the analysis are shown in Figure 16. A few erosion areas lie upstream of the I-40 bridge, but most are found between I-40 and Central Avenue, and between Rio Bravo Boulevard and the South Diversion Channel. Most of these bank erosion areas are associated with expanding bars. In some cases, once the bars 
have grown large enough, they can concentrate and force flow against the opposite banks. The erosion near the South Diversion Channel, over $50 \mathrm{~m}$ since 1992 in some locations, is caused by island expansion leading to a more meandering river planform in this location (Figure 16). Other apparent causes of erosion include upstream bank protection measures (areas 14 and 19), and channel constrictions (areas 9, 10, and 11). Erosion rates at individual locations (Figure 17) appear to vary widely, which is likely associated with the error in creating the polygons, as well as spatial and temporal differences in channel configuration at each location.

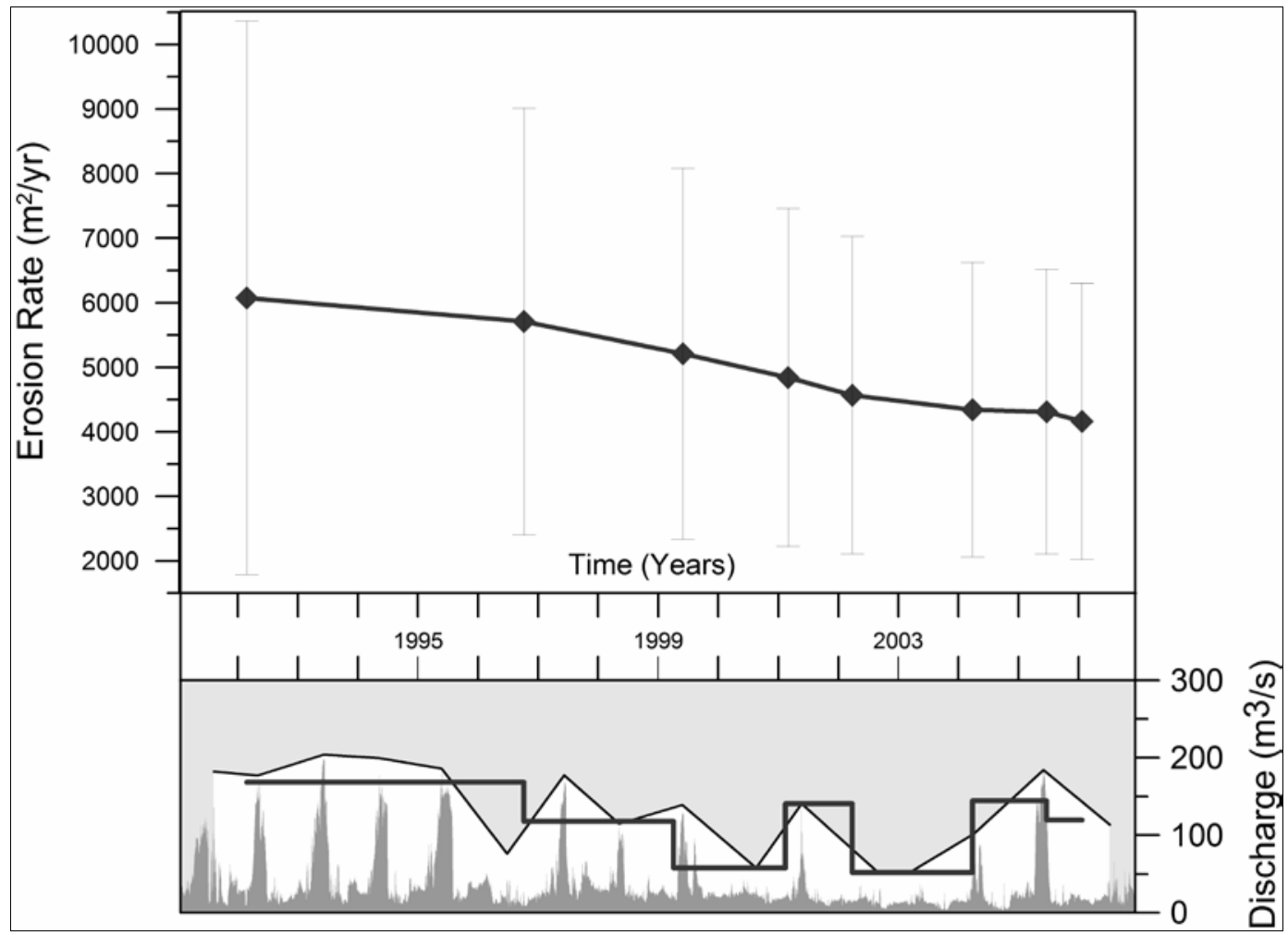

Figure 15. Erosion rates between 1985 and each photograph year. Downward trend suggests that erosion rate is decreasing over time. Discharge metrics as in Figure 3. 


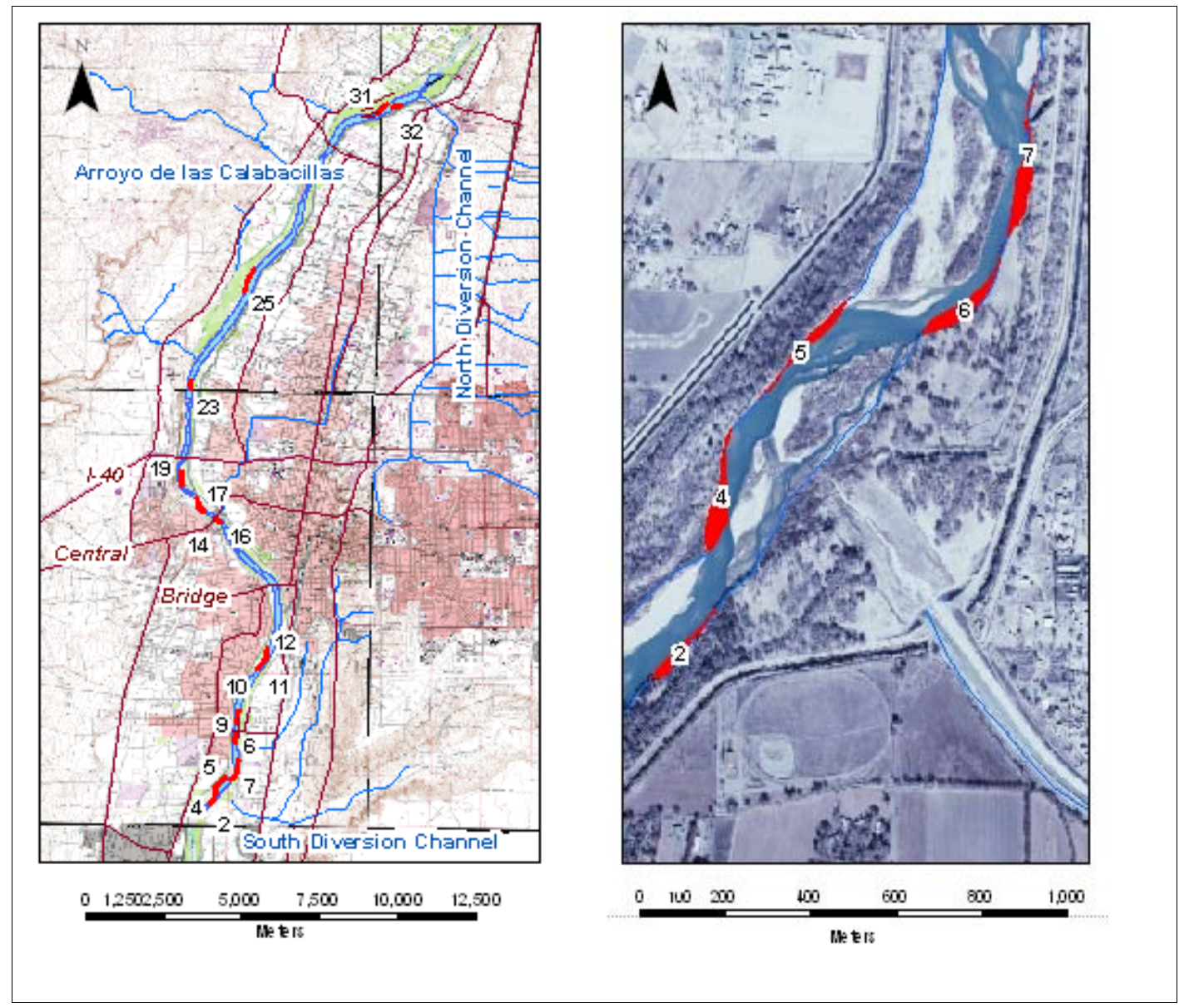

Figure 16. Distribution of relative high bank erosion along study reach (left). Most of these areas are associated with large expanding or attached bars, such as those at South Diversion Channel (right). 

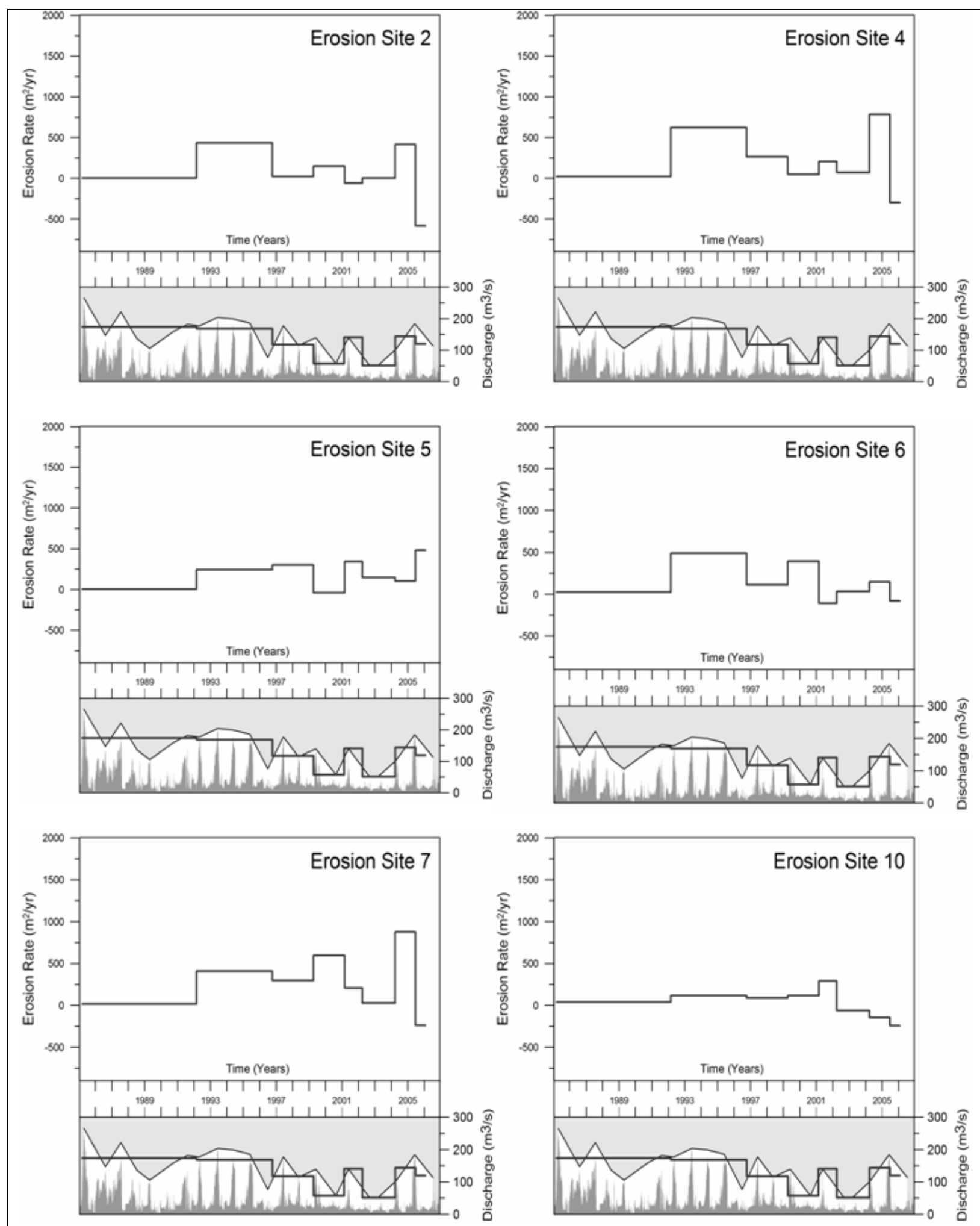

Figure 17. Erosion rates at individual bank locations. Locations are provided in Figure 16. (Sheet 1 of 3) 

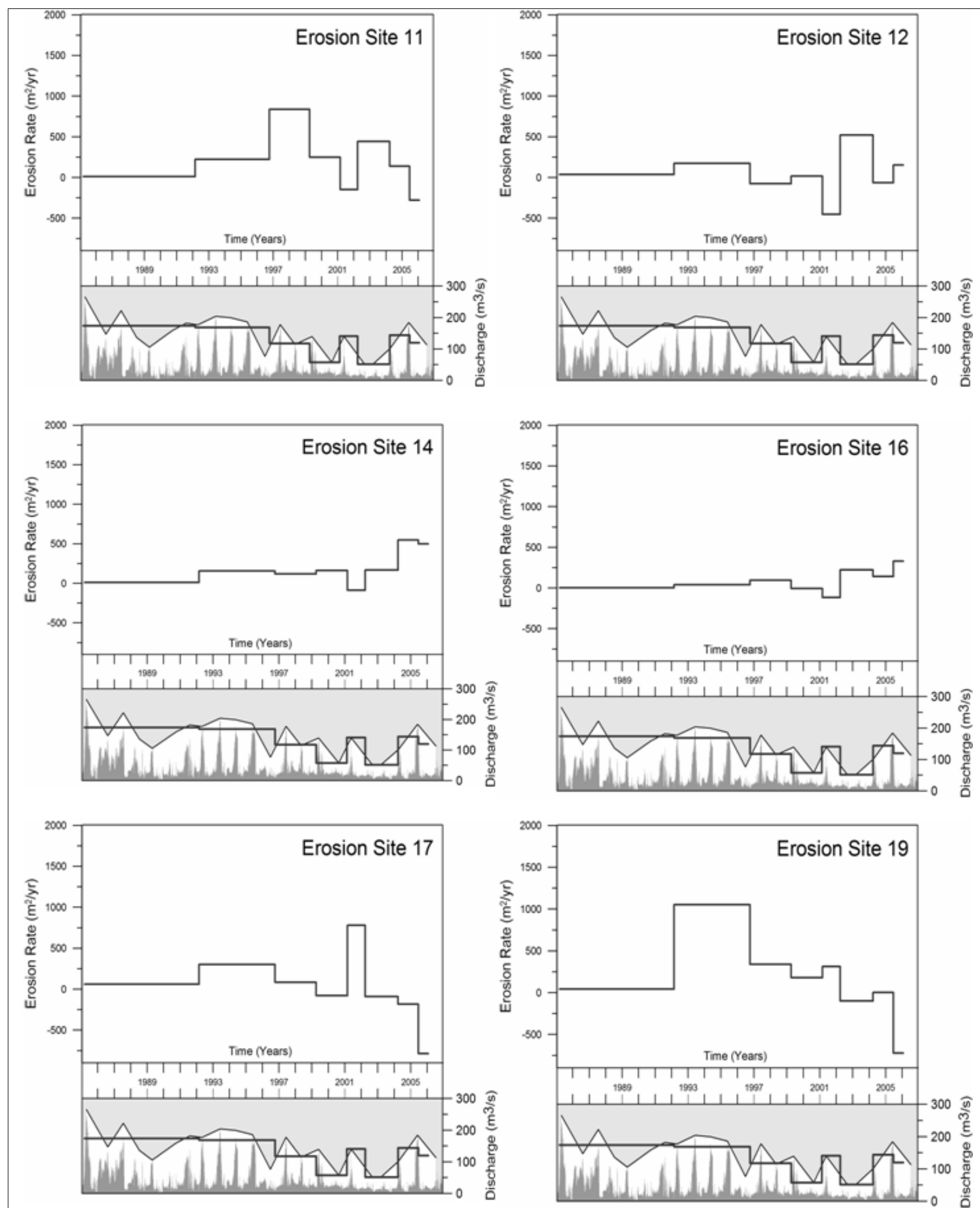

Figure 17. (Sheet 2 of 3). 


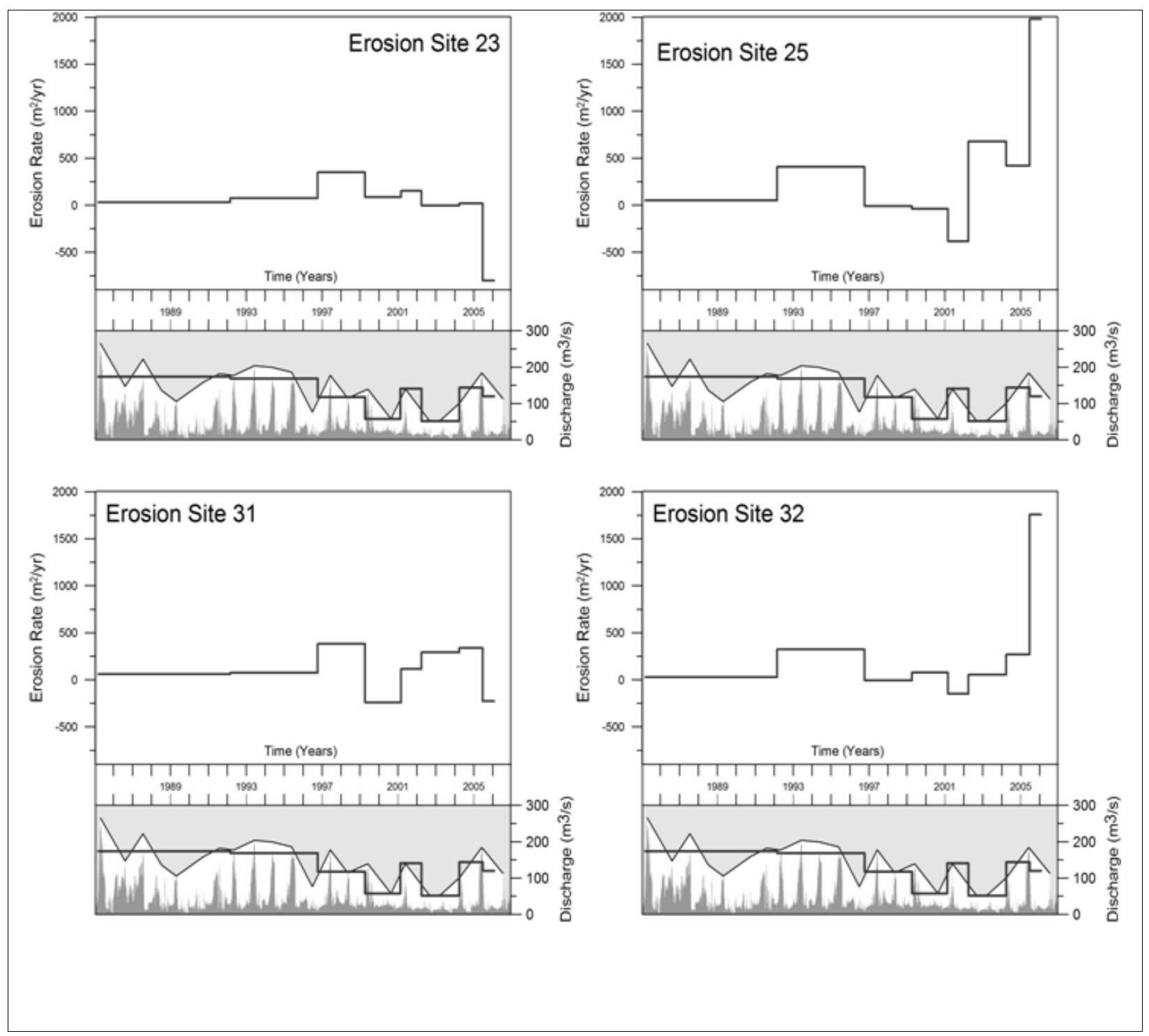

Figure 17. (Sheet 3 of 3). 


\section{River Bed Bathymetry from Aerial Photography}

\section{Introduction}

Information on channel topography is traditionally obtained by measuring cross sections at intervals across the river and extrapolating the data between these cross sections. This method is time consuming and spatially restrictive, in that large numbers of cross sections are often needed to gain an acceptable level of detail. Relying on cross-section data is also an issue when analyzing historical patterns or working in remote areas. River scientists, therefore, often need to turn to alternative methods in order to describe submerged channel features, and an increasing number of investigations are utilizing satellite imagery and aerial photographs to obtain three-dimensional channel data (e.g., Thorne et al. 1993; Winterbottom and Gilvear 1997; J ordan and Fonstad 2005). Winterbottom and Gilvear (1997) developed a technique using black and white photographs to predict bed elevations. The method relies on a good correlation between the gray tones on aerial photographs and water depth from survey data. Variations in gray tone in shallow, clear water rivers with relatively simple geometry relate to variations in the reflectance of light from the river bed. Where conditions are favorable, these methods may provide useful information on bar movement over time, modeling studies requiring detailed channel data, and other pertinent research. As part of this investigation, a simple regression method like that used by J ordan and Fonstad (2005) on the Rio Brazos, TX, was attempted.

\section{Methods}

Cross-section data from established rangelines across the Rio Grande were retrieved from the USBR. Only the 2001 and 2004 data included cross sections within the study area that were collected close to the date that the aerial photographs were collected, limiting the work to these two photograph sets. The spatial coordinates of the cross-section end points were included in the data, and within the GIS, the coordinates for each survey point were produced using the angle between the ends and the given distances along the transect. The river channel was isolated from the rest of the photograph and established island areas were removed from the final channel image. Once processed, the pixel reflectance values were 
extracted to the survey points. Using ArcGIS Spatial Analyst, the image cell sizes were increased from $1 \mathrm{~m}$ to $2.5 \mathrm{~m}$, and $5 \mathrm{~m}$ and pixels were reassigned values with the mean of the surrounding cells at radii of 3,5 , 7.5, and 10 pixels, and comparisons of the resulting pixel values and the calculated depths were made for all of the cases.

\section{Results and discussion}

To date, the air photograph reflectance-depth correlations have generally been weak, and the data have been time-consuming to process. Regression coefficients $\left(\mathrm{R}^{2}\right)$ for the 2001 photograph and the depths from the CA rangelines (CA-4, 6, 9, 12, and 13) covering the river sub-reach near Arroyo de las Calabacillas ranged from 0.02 to 0.22 , and averaged 0.09. The 2004 photographs were not used due to glare recorded within the channel (high sun reflectance). The best result was obtained using a cell size of $2.5 \mathrm{~m}$ and a neighborhood mean within a radius of three cells (Figure 18). At the C0-37 rangeline, downstream of the Rio Bravo Bridge, a slightly better result was obtained. Using the optimum cell size and neighborhood mean above, the relationship between depth and reflectance (based on only one cross section) was $7.69 x+138.14$, with an $R^{2}$ value of 0.45 (Figure 19 ). Although a rigorous check of the data was not performed, the channel bed modeled with the regression equation showed similar bar and channel forms as the 2001 photograph (Figure 20).

The Rio Grande is a difficult river on which to apply this method. Frequent turbid conditions, overhanging vegetation, exposed sand bars, and a rapidly shifting channel bed hinder comparison of the cross sections and photographs. Ideal conditions for utilizing the method would include a shorter study reach, and low to moderate, clear flows. Three or four cross sections should be surveyed in the reach, including at least one control transect, and the imagery and cross-section data should be collected essentially simultaneously (J ordan and Fonstad 2005). 


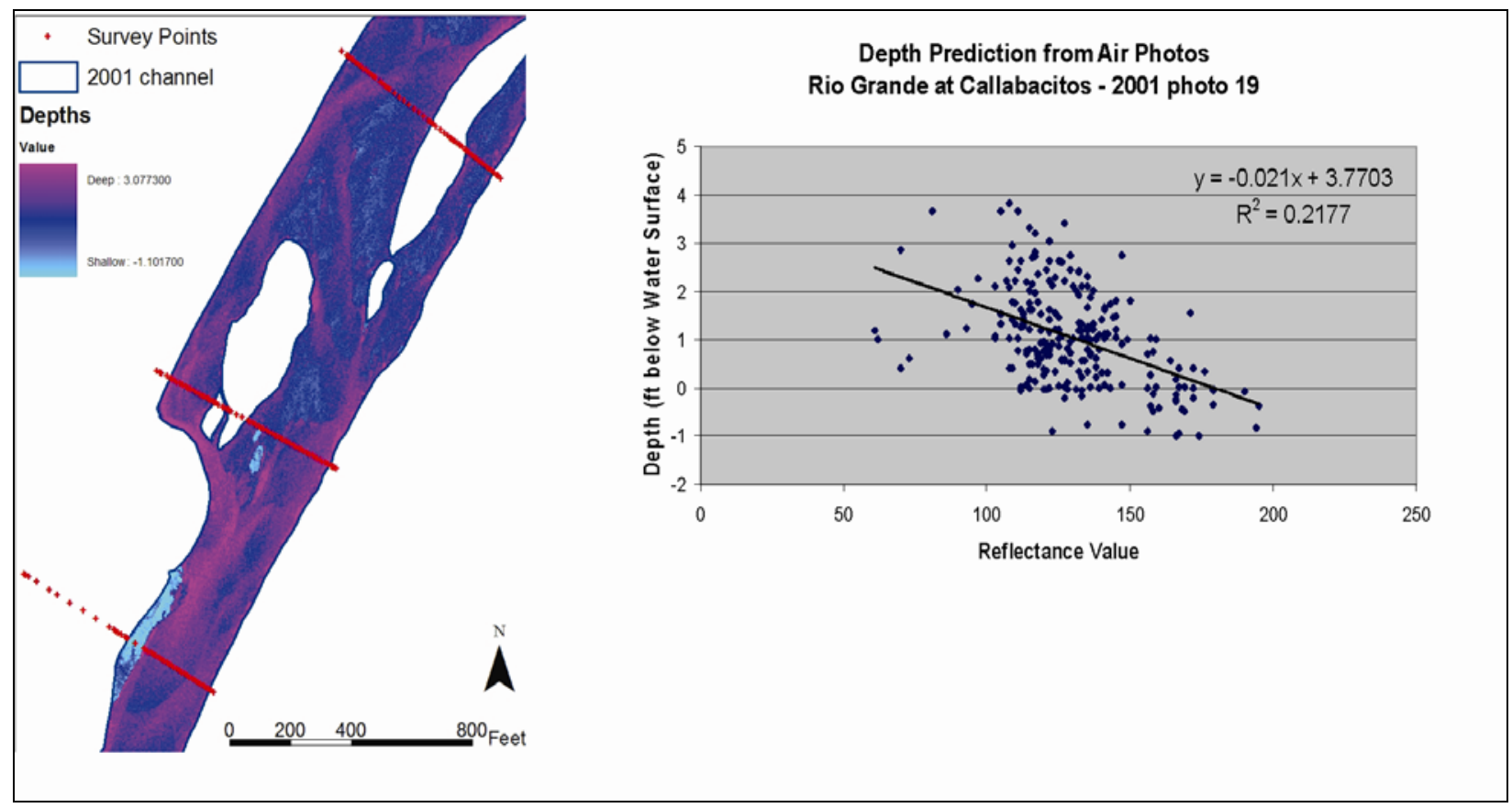

Figure 18. Regression of 2001 air photographs reflectance values and cross-section depths (right) and resulting modeled depths (left).

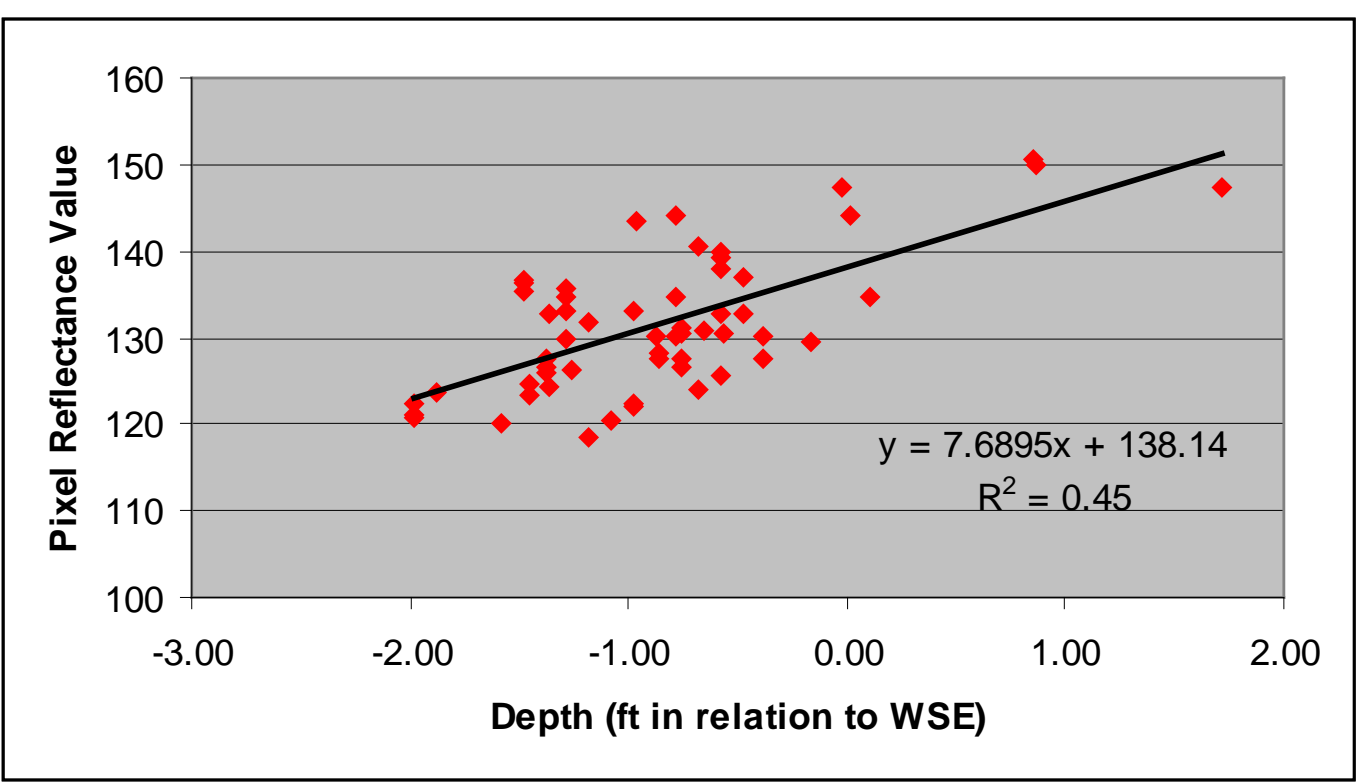

Figure 19. Relationship between photograph reflectance values and depth at USBR cross-section CO-27. 


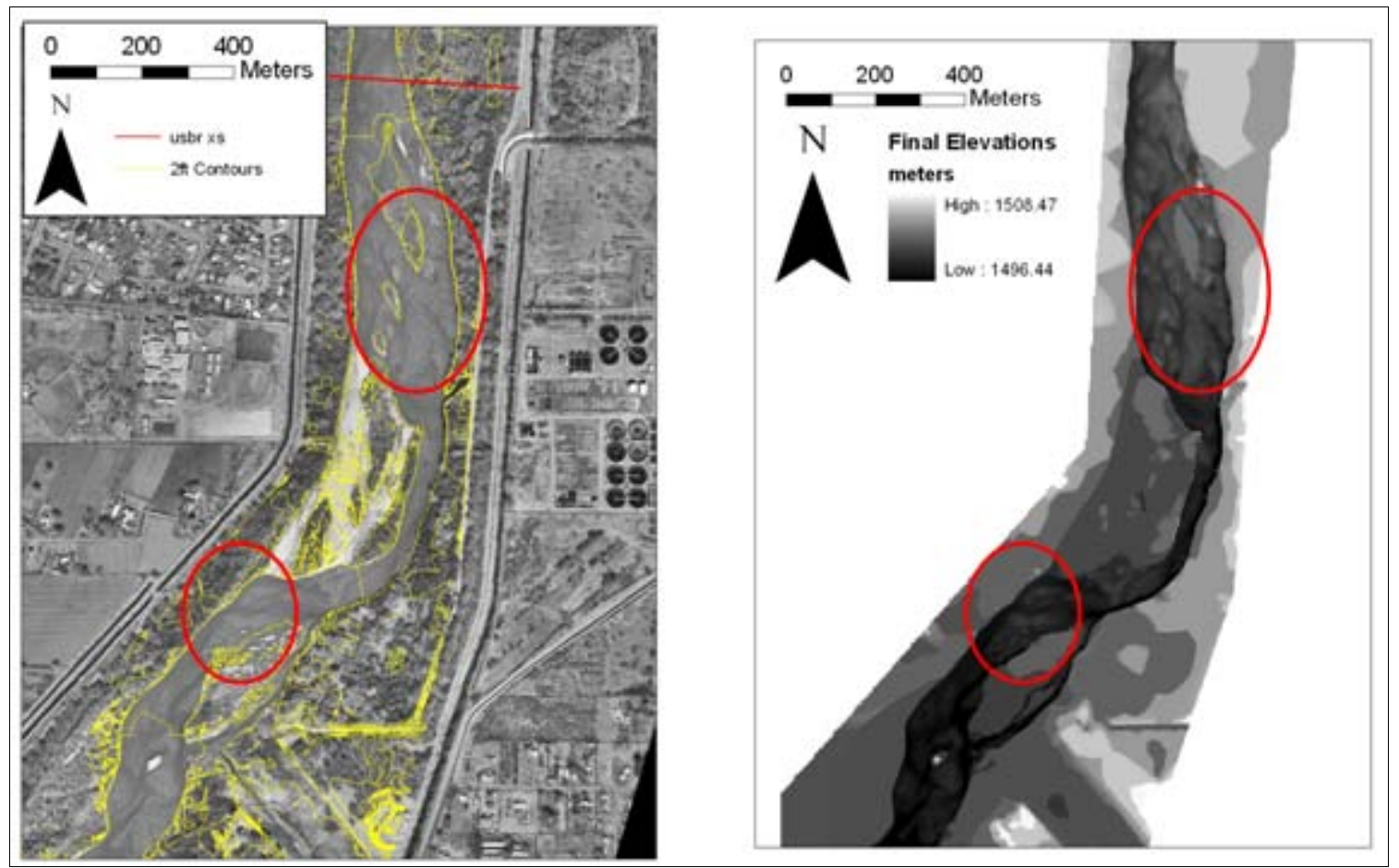

Figure 20. Topographic data derived from 0.6-m (2-ft) contours (yellow) and comparison of air photograph reflectance values and measured cross-section depths (red line at cross-section). Although not quantified at this stage of analysis, the final DEM (right) revealed similar plan view channel features (red ovals) as seen in photograph (left). 


\section{Conclusions}

In general, a historical analysis of channel change using aerial photographs produces useful information concerning channel planform over time. Measuring channel characteristics from spatially referenced photographs in a geographic information system allows for the collection of moderately detailed quantitative data defining channel and bar areas. These data can then be used to locate areas of active bank erosion and channel deposition, and determine rates of change. However, the amount of error in these measurements can often be quite high, limiting final interpretations.

As noted by previous researchers working on different reaches of the Rio Grande, the channel widths and area in the Albuquerque study reach have been decreasing and island area has been increasing since the time period that aerial photographs were taken in 1972. Relationships between the hydrology and channel planform data are tenuous because of relatively large errors associated with delineating channel banks and islands. The data suggest that large peak flows tend to maintain the channel planform configuration, and channel narrowing occurs during periods characterized by low peak discharges. The timing of the changes in the study reach can be linked to diminished peak flows associated with the closure of Cochiti Dam, upstream of the study reach, in 1973 and a period of drought in the late 1900s and early 2000s. However, the channel was narrowing even more rapidly during the first half of the $20^{\text {th }}$ century (Makar et al. 2006), and some of the documented adjustments might be a continuation of those changes and the initial management reactions to them. Similar relationships have been documented on other sand-bed rivers in the arid-West, including the Cimarron River, NM (Schumm and Lichty 1963), and the Platte River, NB (J ohnson 1994).

Few locations along the study reach experienced substantial bank erosion, and the few banks that are eroding are typically opposite of expanding or bank-attached islands in the channel. Rates of erosion relative to the 1985 banklines appear to be decreasing, and between photograph years, erosion rates may have been dropping through the beginning of the recent drought period, but then may have increased at the end of the drought through the 2005 flood. As with the channel data, large amounts of uncertainty in the erosion data make interpretation difficult. 
Finally, alternative uses for remotely sensed data, either aerial photography or satellite imagery, are being developed rapidly, creating numerous opportunities for furthering river research. The use of such imagery to derive three-dimensional geomorphic data is an important area of exploration in this research, but its application appears limited to unusual clear-water conditions on the Rio Grande. More field and photographic analytical work is necessary to develop useful methods for using imagery to model river-bed topography in the Rio Grande. 


\section{References}

Friedman, J. M., W. R. Osterkamp, and W. M. Lewis. 1996. The role of vegetation and bed-level fluctuations in the process of channel narrowing. Geomorphology 14:341-351.

Gilvear, D. J., S. J. Winterbottom, and H. Sichingbula. 1999. Character of meander planform change on the Luangwa River, Zambia. Earth Surface Processes and Landforms 16:1-24.

Graf, W. L. 2000. Locational probability for a dammed, urbanizing stream: Salt River, Arizona, USA. Environmental Management 25(3):321- 335.

Gurnell, A. M. 1997. Channel change on the River Dee meanders, 1946- 1992, from the analysis of air photographs. Regulated Rivers: Research and Management 13:1326.

Hughes, M. L., P. F. McDowell, and W. A Marcus. 2006. Accuracy assessment of georectified aerial photographs: Implications for measuring lateral channel movement in a GIS. Geomorphology 74:1-16.

Johnson, W. C. 1994. Woodland expansion in the Platte River, Nebraska: Patterns and causes. Ecological Monographs 64(1):45-84.

J ordan, D. C., and M. A. Fonstad. 2005. Two dimensional mapping of river bathymetry and power using aerial photography and GIS on the Brazos River, Texas. Geocarto International 20(3):322-356.

Lagasse, P. F. 1994. Variable response of the Rio Grande to dam construction. In: The Variability of Large Alluvial Rivers, S. A. Schumm and B. R. Winkley, eds. New York, NY: American Society of Civil Engineers Press, 395-422.

Lapointe, M. F., and M. A. Carson. 1986. Migration patterns of an asymmetric meandering river: the Rouge River, Quebec. Water Resources Research 22:731743.

Lawler, D. M. 1993. The measurement of river bank erosion and lateral channel change: A review. Earth Surface Processes and Landforms 18:777- 821.

Leon, C. 1998. Morphology of the Middle Rio Grande from Cochiti Dam to Bernalillo Bridge, NM. Unpublished M.S. thesis. Ft. Collins, CO: Colorado State University. Summer 1998.

Leung, Y., and J . P. Yan. 1998. A locational error model for spatial features. International J ournal of Geographical Information Science 12(6):607-620.

Makar, P., T. Massong, T. Bauer, P. Tashjian, and K. J. Oliver. 2006. Channel width and flow regime changes along the Middle Rio Grande, NM. J oint $8^{\text {th }}$ Federal Interagency Sedimentation Conference and $3^{\text {rd }}$ Federal Interagency Hydrologic Modeling Conference. Reno, NV. 
Massong, T. 2005. Bank Erosion Report - San Acacia Reach of the Rio Grande, NM. Unpublished report for the U.S. Department of the Interior, Bureau of Reclamation, Albuquerque, NM, December 2005.

Massong, T., and P. Makar. 2006. Evolution of the bends at Rio Grande RM 110. Unpublished report for the U.S. Department of the Interior, Bureau of Reclamation, Albuquerque, NM, February 2006.

Massong, T., P. Tashjian, and P. Makar. 2006. Recent channel incision and floodplain evolution within the Middle Rio Grande, NM. J oint $8^{\text {th }}$ Federal Interagency Sedimentation Conference and $3^{\text {rd }}$ Federal Interagency Hydrologic Modeling Conference. Reno, NV.

Mussetter Engineering, Inc. 2003. Geomorphic and sedimentologic investigations of the Middle Rio Grande between Cochiti Dam and Elephant Butte Reservoir. Report prepared for New Mexico Interstate Stream Commission by Mussetter Engineering, Inc., Fort Collins, CO.

Mussetter Engineering, Inc. 2006. Evaluation of bar morphology, distribution and dynamics as indices of fluvial processes in the Middle Rio Grande, New Mexico. Unpublished report for the New Mexico Interstate Stream Commission by Mussetter Engineering, Inc., Fort Collins, CO.

Meyer, G., and C. Hepler. 2007. Vegetated island formation and change in the Middle Rio Grande near Albuquerque, NM. Unpublished report for the U.S. Department of the Interior, Bureau of Reclamation, Albuquerque, NM. Cooperation Agreement 01-FC-40-4670, 9 April 2007.

O'Connor, J. E., M. A. J ones, and T. L. Haluska. 2003. Flood plain and channel dynamics of the Quinault and Queets Rivers, Washington, USA. Geomorphology 51:31-59.

Oliver K. J . 2004. Middle Rio Grande Project - 1918-2002 geomorphology study for the Rio Grande from Velarde to the Narrows of Elephant Butte, New Mexico. Denver, CO: Remote Sensing and GIS Group, Technical Service Center, U. S. Department of the Interior, Bureau of Reclamation.

Ortiz, R. 2004. A river in transition: Geomorphic and bed sediment response to Cochiti Dam on the Middle Rio Grande, Bernalillo to Albuquerque, NM. Unpublished thesis. Albuquerque, NM: Department of Earth and Planetary Science, University of New Mexico.

Richard, G., and P. J ulien. 2003. Dam impacts on and restoration of an alluvial river Rio Grande, New Mexico. International J ournal of Sediment Research 18(2):8996.

Scurlock, D. 1998. From the Rio to the Sierra: An environmental history of the Middle Rio Grande Basin. RMRS-GTR-5. Fort Collins, CO: U.S. Department of Agriculture, Forest Service, Rocky Mountain Research Station.

Schumm, S. A., and R. W. Lichty. 1963. Channel widening and floodplain construction along Cimarron River in southwestern Kansas. U.S. Geological Survey Professional Paper 352-D. 
Surian, N. 1999. Channel changes due to river regulation. Earth Surface Processes and Landforms 24:1135-1151.

Tashjian, P., and T. Massong. 2005. The implications of recent floodplain evolution on habitat within the middle Rio Grande, New Mexico. Unpublished Report for the U.S. Department of the Interior, Bureau of Reclamation, Albuquerque, NM.

Taylor, J . R. 1982. An introduction to error analysis: The study of uncertainties in physical measurements. Mill Valley, CA: University Science Books.

Thorne, C. R., A. P. G. Russell, and M. K. Alam. 1993. Planform pattern and channel evolution of the Brahmaputra River, Bangladesh. In: Braided Rivers, J. L. Best and C. S. Bristow, eds. The Geological Society Special Publication No. 75. London: Geological Society, 257-277.

Trimble, S. 1991. Historical sources of information for geomorphological research in the United States. Professional Geographer 43(2):212-228.

Winterbottom, S. J . and D. J . Gilvear. 1997. Quantification of channel bed morphology in gravel-bed rivers using airborne multispectral imagery and aerial photography. Regulated rivers: Research and Management 13:489-499. 


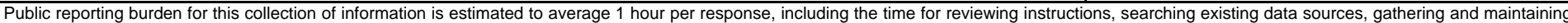

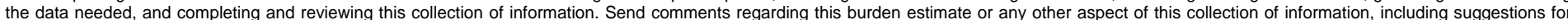

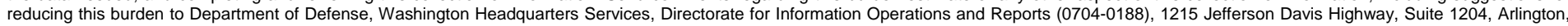

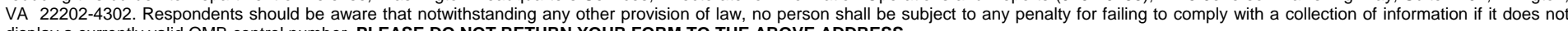
display a currently valid OMB control number. PLEASE DO NOT RETURN YOUR FORM TO THE ABOVE ADDRESS.
1. REPORT DATE (DD-MM-YYYY)
August 2010

\section{TITLE AND SUBTITLE}

Coupling of Hydrologic/Hydraulic Models and Aerial Photographs Through Time, Rio Grande Near Albuquerque, New Mexico: Report Documentary 2007 Work
3. DATES COVERED (From - To)

5a. CONTRACT NUMBER

5b. GRANT NUMBER

5c. PROGRAM ELEMENT NUMBER

5d. PROJECT NUMBER

5e. TASK NUMBER

5f. WORK UNIT NUMBER

8. PERFORMING ORGANIZATION REPORT NUMBER

ERDC/CHL CR-10-2

University of New Mexico

MSC01 1070 Civil Engineering

Albuquerque, NM 87120

9. SPONSORING I MONITORING AGENCY NAME(S) AND ADDRESS(ES)

10. SPONSOR/MONITOR'S ACRONYM(S)

U.S. Army Corps of Engineers

Coastal and Hydraulics Laboratory

3909 Halls Ferry Road

Vicksburg, MS 39180-6199

11. SPONSOR/MONITOR'S REPORT NUMBER(S)

\section{DISTRIBUTION / AVAILABILITY STATEMENT}

Approved for public release; distribution is unlimited.

\section{SUPPLEMENTARY NOTES}

\section{ABSTRACT}

This phase of the study investigated the relation of average and peak flows in the Rio Grande to changes in channel, sand bar, and island widths as measured on historical aerial photographs taken from 1972 to 2006. The study reach lies between Bernalillo Bridge and the Isleta Diversion Dam, with a focus on the river between the North and South Albuquerque Metropolitan Arroyo Flood Control Authority (AMAFCA) Diversion Channels. Digitized and georeferenced photographs were analyzed using a geographic information system (GIS), with particular attention paid to quantifying potential measurement error and its propagation through estimates of channel areas and bank erosion rates. Average active channel widths decreased from $169 \pm 5 \mathrm{~m}$ in 1972 to $130 \pm 5 \mathrm{~m}$ in 2006. Narrowing concentrated in the upper study reach and in areas where the 1972 channel was relatively wide. Variability in channel width also decreased over the study period. Decreases in channel width and area coincide with periods of low flows, although the area changes are associated with large errors. Island areas have increased since 1972, although islands per se were also lost during the later study period by bank attachment. Bank erosion estimates have large associated errors. Erosion rates appear to be generally decreasing over time, but accelerated during the 2005 high flows.

\begin{tabular}{ll}
\hline 15. SUBJECT TERMS & Channel Erosion \\
Aerial Photography & Channel Morphology \\
Arid Regions & GIS \\
\hline
\end{tabular}

16. SECURITY CLASSIFICATION OF:

\begin{tabular}{|c|} 
LIMITATION \\
OF ABSTRACT
\end{tabular}

Streambank Erosion

Urban Flood Demonstration Program

\begin{tabular}{l|l|}
$\begin{array}{l}18 . \\
\text { NUMBER } \\
\text { OF } \\
\text { PAGES }\end{array}$ & $\begin{array}{l}\text { 19a. NAME OF RESPONSIBLE } \\
\text { PERSON }\end{array}$ \\
\cline { 2 - 2 } 54 & $\begin{array}{l}\text { 19b. TELEPHONE NUMBER (include } \\
\text { area code) }\end{array}$ \\
\hline
\end{tabular}

